Disponível em

ANRAD http://www.anpad.org.br/rac

RAC, Rio de Janeiro, v. 19, Edição Especial, art. 4, pp. 53-76, Maio 2015

http://dx.doi.org/10.1590/1982-7849rac20151999

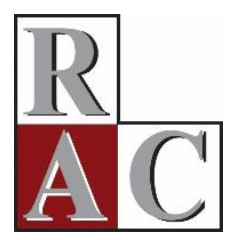

(cc) EY-NC

\title{
Capital Bancário e Crédito no Brasil
}

\author{
Bank Capital and Lending in Brazil
}

Valter Takuo Yoshida Junior Banco Central do Brasil

Rafael Felipe Schiozer Fundação Getulio Vargas - FGV/EAESP 


\title{
Resumo
}

Este estudo investiga a associação entre capital bancário e concessão de crédito livre no mercado brasileiro de 2003 a 2012, adaptando a metodologia de Berrospide e Edge (2010). Inicialmente, estimamos um capital alvo de longo prazo, ativamente gerenciado pelos bancos, e então calculamos seu capital excedente. Em uma segunda etapa, investigamos se este capital excedente está associado à variação do crédito livre concedido pelos bancos, utilizando regressão de dados em painel. Os resultados indicam relação positiva entre o crescimento do crédito livre e o capital excedente, mais forte na segunda parte do período de análise (após setembro de 2008), mas ainda assim economicamente modesta, contrariando a premissa da alavancagem constante. Os resultados são robustos à utilização de indicadores contábeis diretamente observáveis para o capital bancário. Não se encontrou relação significante entre o capital e o crescimento do crédito nos bancos públicos.

Palavras-chave: capital bancário; crédito bancário; capital alvo; capital excedente.

\begin{abstract}
This paper investigates the relationship between bank capital and lending in the Brazilian market from 2003 to 2012, by adapting the methodology used by Berrospide and Edge (2010). Initially, we estimate a long-term target capital, actively managed by each bank, and then we compute the banks' capital surpluses. In a second step, we investigate whether this capital surplus is related to the change in non-earmarked credit using panel data regressions. The results show a positive relationship between the change in loans and the capital surplus, stronger in the second part of the sample period (after September/2008), but yet economically modest, contradicting the assumption of constant leverage. Similar results are obtained using direct observable accounting indicators of bank capital. There is no significant relationship between capital and credit growth in governmental banks.
\end{abstract}

Key words: bank capital; bank credit; capital target; capital surplus. 


\section{Introdução}

A relação entre o capital bancário e o volume de crédito concedido vem sendo estudada pelo menos desde a adoção do primeiro Acordo de Basileia de 1988 (Berger \& Udell, 1994; Bernanke \& Lown, 1991; Berrospide \& Edge, 2010; Elliott, 2010; Hancock \& Wilcox, 1993), que estabeleceu um limite de empréstimos para as instituições financeiras, proporcional ao seu patrimônio, tornando o capital uma possível restrição para a ampliação da carteira de crédito.

Atualmente, com a gradual entrada em vigência das normas introduzidas pelo terceiro Acordo de Basileia, mais estrito quanto à quantidade e qualidade do capital requerido, vem se intensificando o debate sobre a relação entre o capital bancário, o crescimento dos empréstimos e seus efeitos macroeconômicos. Em tese, a maior exigência de capital traz estabilidade financeira, mas pode trazer efeitos negativos para a oferta de crédito, sugerindo um tradeoff entre estabilidade do sistema e concessão de crédito (Elliott, 2010).

Berrospide e Edge (2010) argumentam que a magnitude do efeito da variação do capital sobre o crédito depende do grau em que o capital constitui uma restrição. Em um cenário em que as imperfeições de mercado são irrelevantes, variações no capital não deveriam interferir na capacidade de um banco conceder crédito. No outro extremo, se um banco gerencia ativamente seu capital almejando uma alavancagem $L$ ótima, e não é capaz de ajustar o capital para fazer frente a choques, uma variação de uma unidade monetária no capital causaria uma mudança de $L$ unidades monetárias nos ativos na mesma direção.

Para Flannery e Rangan (2008), os ajustes no capital são realizados a uma velocidade que considera, por um lado, os custos de manutenção de capital em excesso e, por outro, os custos de regulação. Eles encontram evidências de que bancos dos EUA possuem alvos de longo prazo para a estrutura de capital e que a gerenciam ativamente. Chamam de capital excedente (capital surplus) a diferença percentual, positiva ou negativa, entre o capital observado e o alvo.

O objetivo deste estudo ${ }^{(1)}$ é investigar a associação entre variações no capital excedente e o crescimento do volume de crédito livre no mercado bancário brasileiro entre 2003 e 2012. Seus questionamentos fundamentais são: (a) variações no capital excedente de um banco estão associadas a variações em sua carteira de empréstimos? (b) essa associação é estável ao longo do tempo? A resposta a estas questões contribui para o debate e auxilia em desenhos regulatórios relacionados à exigência de capital.

A metodologia é composta de duas etapas. Na primeira, estimamos o capital alvo, gerenciado pelos bancos, e o capital excedente. Na segunda, investigamos se o capital excedente associa-se às variações no volume de crédito.

Os resultados apontam para uma relação positiva, mas economicamente modesta, entre capital e crédito. $\mathrm{O}$ acréscimo de $\mathrm{R} \$ 1$ no capital está associado ao crescimento da carteira de crédito livre em cerca de $\mathrm{R} \$ 0,11$ no período de março de 2003 a junho de 2008, e em cerca de $\mathrm{R} \$ 0,24$ no período de setembro de 2008 a dezembro de 2012. Os resultados são robustos à utilização de medidas contábeis e regulatórias diretamente observáveis de capital no lugar do capital excedente estimado.

A maior sensibilidade do crédito a variações no capital na segunda parte do período amostral não surpreende. As características macroeconômicas e institucionais do Brasil sofreram modificações importantes entre 2003 e 2012. A participação do crédito no PIB cresceu de 23,6\% em março de 2003 para 53,8\% em dezembro de 2012, segundo dados do Banco Central. A liquidez global diminuiu, especialmente a partir do final de 2008, aumentando o custo de oportunidade do capital. O crédito passou a ser a atividade principal de um maior número de bancos, e as medidas macroprudenciais editadas após a crise financeira mundial passaram a exigir temporariamente maior alocação de capital para certas modalidades de crédito. 
Os resultados indicam ainda que a sensibilidade do crédito a variações no capital é menor em bancos públicos, consistente com o pressuposto de que bancos públicos enfrentam menores restrições de capital e de que tenham adotado uma política de ampliação da carteira de crédito, em especial após a crise financeira do final de 2008. Enquanto os bancos privados reduziram a concessão de crédito durante a crise que se seguiu à quebra do Lehman Brothers, os bancos públicos apresentaram crescimento em praticamente todo o período, mesmo após a crise (Oliveira, Schiozer, \& Leão, 2014).

Além desta introdução, este trabalho é composto pelas seguintes seções: revisão da literatura; hipóteses e metodologia; dados e panorama do crédito no Brasil; resultados e conclusão.

\section{Revisão da Literatura}

Em bancos, a estrutura de capital ótima é determinada pelo trade-off entre a criação de liquidez e de oferta de crédito e a estabilidade do banco (Diamond \& Rajan, 2000). Assim, diferentes estruturas de capital estão intrinsecamente associadas a diferentes índices de liquidez e concessão de crédito, e determinam, portanto, o perfil ótimo de risco do banco.

Diversos estudos investigam a redução do crédito bancário ocorrida nos EUA no início da década de 90, e não há consenso sobre o papel do capital bancário nessa redução. Bernanke e Lown (1991) encontram evidências de que uma crise de capital afetou negativamente a concessão de crédito, principalmente nos bancos pequenos. Hancock e Wilcox (1993) mostram que as políticas internas de alavancagem dos bancos explicam melhor a redução do crédito do que a introdução do capital imposto pelos reguladores. Berger e Udell (1994) e Peek e Rosengreen (1995) também não encontram evidências de que a crise de capital ou a necessidade de aumento na capitalização decorrente dos padrões do Acordo de Basileia tenha desencadeado uma realocação no crédito dos bancos dos EUA.

Outros estudos focam na heterogeneidade entre os bancos para entender como variações nas condições macroeconômicas e de capital afetam o crédito. Hancock e Wilcox (1998) concluem que uma diminuição no capital reduz mais o volume de crédito ofertado aos pequenos negócios pelos bancos pequenos do que pelos bancos grandes nos EUA. Gambacorta e Mistrulli (2004) estudam instituições financeiras italianas e constatam que instituições bem capitalizadas protegem melhor seu volume de crédito de choques no PIB ou na política monetária. Esse efeito ocorre por dois canais: (a) bancos mais capitalizados têm mais acesso a financiamento (bank lending channel); (b) bancos com menor descasamento de maturidades entre ativos e passivos são mais capacitados a superar dificuldades financeiras sistêmicas que se propagam pelos tomadores (bank capital channel). O canal do capital atua mais fortemente nos bancos pequenos, que têm maior descasamento de prazos.

Outros estudos mostram relação positiva entre capital excedente e crédito. Francis e Osborne (2009) encontram relação positiva, mas economicamente modesta, entre capital excedente e crédito no Reino Unido; Berrospide e Edge (2010) também encontram relação positiva e modesta nos EUA. As evidências de Brei, Gambacorta e Peter (2013) apontam que uma maior capitalização promove o crescimento do crédito em tempos normais; mas, em um período de crise, a capitalização adicional tem efeito somente se exceder um limite crítico.

No Brasil, Blum e Nakane (2005) encontram relação positiva entre o índice de Basileia e a oferta de crédito. Essa relação é modesta em bancos que atendem ao limite regulamentar de capital, e acentuada nos bancos que não atendem. Dawid e Takeda (2011) mostram que as medidas macroprudenciais adotadas em 2010, como a alteração na alocação de capital regulatório, reduziram o crédito à pessoa física, principalmente nos bancos de menor porte, ao passo que Takeda e Dawid (2013) e Martins e Schechtman (2013) concluem que essas medidas tiveram impacto nas taxas de juros cobradas nos empréstimos. 


\section{Hipóteses e Metodologia}

Flannery e Rangan (2008) encontram evidência de que os bancos dos EUA possuem uma meta de capital de longo prazo, e o gerenciam ativamente. Partindo do pressuposto da existência de um capital alvo, Berrospide e Edge (2010) definem o capital excedente (capital surplus) como o desvio do nível de capital observado relativamente ao capital alvo.

$$
\text { Capital excedente } e_{i, t}=\left(k_{i, t}-k_{i, t}^{*}\right) / k_{i, t}^{*}
$$

Onde $k_{i, t}$ é o índice de capital (capital próprio/ativo) observado no banco $i$ no momento $t$; e $k_{i, t}^{*}$ é o índice de capital alvo para o banco $i$ em $t$.

A primeira hipótese deste trabalho relaciona capital excedente e crescimento do crédito.

Hipótese 1: O capital excedente relaciona-se positivamente com o crescimento do crédito.

O teste da hipótese 1 requer duas etapas. Na primeira, estima-se o capital alvo e o capital excedente para cada banco a cada período. Na segunda, estima-se um modelo que relaciona variação no crédito com a estimativa de capital excedente. Não se pretende inferir causalidade, mas apenas encontrar associações entre capital e crédito.

\section{Estimativa do capital alvo e capital excedente}

A estimativa do capital alvo é feita adaptando a proposta de Berrospide e Edge (2010). O capital alvo é determinado pelos bancos a partir de suas características, e o excesso (ou falta) de capital é considerado em relação a esse alvo, e não a um índice regulamentar fixo. $\mathrm{O}$ modelo adaptado considera o capital alvo dado por:

$$
k_{i, t+1}^{*}=\alpha_{i}+\theta \boldsymbol{X}_{i, t}
$$

Onde $k_{i, t+1}^{*}$ é o índice de capital alvo do banco $i$ no momento $t+1 ; \alpha_{i}$ é um efeito fixo por banco, que considera a heterogeneidade não observada entre bancos, constante ao longo do tempo; $\boldsymbol{X}_{i, t}$ é um vetor de variáveis específicas de cada banco (determinantes do capital alvo) e; $\theta$ é o vetor de coeficientes a serem estimados.

O modelo de ajuste parcial é dado por:

$$
k_{i, t+1}-k_{i, t}=\lambda\left(k_{i, t+1}^{*}-k_{i, t}\right)+\tilde{\delta}_{i, t+1}
$$

Onde $k_{i, t}$ é o índice de capital do banco $i$ em $t ; \lambda$ é a velocidade média de ajuste (considerada constante); e $\tilde{\delta}_{i, t+1}$, o termo de erro.

A partir da equação 2, pode-se rearranjar a equação 3, obtendo:

$$
k_{i, t+1}=\alpha_{0}+\lambda \alpha_{i}+(\lambda \theta) \boldsymbol{X}_{i, t}+(1-\lambda) k_{i, t}+\tilde{\delta}_{i, t+1}
$$

Onde $\alpha_{0}$ é uma constante.

No modelo de Berrospide e Edge (2010), o vetor $\boldsymbol{X}_{i, t}$ inclui variáveis macroeconômicas (inflação, taxa básica de juros e PIB). Neste trabalho, substituímos essas variáveis por uma série de dummies de tempo, uma vez que não há interesse específico nos coeficientes dessas variáveis. Esse procedimento captura todas as flutuações que afetam uniformemente o capital alvo dos bancos ao longo do tempo (inclusive a sazonalidade). A estimação do capital alvo é feita com a seguinte equação:

$$
k_{i, t}=\alpha_{0}+\lambda \alpha_{i}+(1-\lambda) k_{i, t-1}+\lambda \theta \boldsymbol{X}_{i, t-1}+\omega^{\prime} \operatorname{tri}_{t}+\epsilon_{i, t}
$$


Onde tri $_{t}$ são dummies de tempo referentes a cada período $t ; \omega$ 'é o vetor de coeficientes relativos a essas dummies; e $\epsilon_{i, t}$, o termo de erro.

O vetor de variáveis de controle $\boldsymbol{X}_{i, t}$ é composto por:

- Dummies por quintil de tamanho (Ativo Total): a proxy para tamanho reflete especificidades na composição da carteira (por exemplo, maior diversificação) e acesso facilitado a fontes de financiamento e, consequentemente, menor necessidade de capital próprio (Berrospide \& Edge, 2010). O uso de dummies visa capturar efeitos não lineares e minimizar o ratio variable problem (existente se a variável de interesse PL/AT fosse utilizada simultaneamente com o logaritmo natural do Ativo Total). As dummies de tamanho foram geradas a partir da divisão da amostra em cinco grupos conforme o Ativo Total em cada período.

Retorno sobre o Ativo (ROA) e quadrado do Retorno sobre o Ativo $\left(\mathrm{ROA}^{2}\right)$ (Berrospide \& Edge, 2010): incluídos como proxy para ganhos. O aumento nos lucros reflete uma acumulação de ganhos retidos e de capital. A inclusão do quadrado do Retorno sobre o Ativo captura o efeito não-linear do ROA sobre o capital.

- Baixa de Crédito de Liquidação Duvidosa sobre o Ativo Total (BCLD/AT): a variável é proxy para risco do banco e captura a maior necessidade de capital imposta pelo mercado e pelos reguladores (Berrospide \& Edge, 2010).

- Dummy para pressão regulatória: a pressão regulatória pode afetar o índice de capital. Berrospide e Edge (2010) utilizam um indicador que assume o valor 1 caso a relação PL/AT for menor que 6,5\%, mas essa definição faria pouco sentido no Brasil. Nesse caso, seguimos Saito e Pereira (2012): a dummy que reflete pressão regulatória recebe valor 1 caso o índice de Basileia esteja abaixo do percentil $10 \%$ da distribuição no período, ou 0 , caso contrário.

Em especificações alternativas, usadas como robustez, o vetor $\boldsymbol{X}_{i, t}$ inclui também as variáveis Ativos Líquidos/Ativo Total e Crédito/Ativo Total, adaptadas de Berrospide e Edge (2010). Optou-se pela especificação principal sem essas duas variáveis, pois: (a) sua inclusão poderia trazer simultaneidade entre o capital excedente e o crescimento do crédito na segunda etapa e; (b) as variáveis dependente e independente constituídas como quocientes com o mesmo denominador gerariam relação mecânica entre as variáveis. Suas definições são:

Ativos Líquidos/Ativo Total (Ativos Líquidos/AT): definida como a soma de três rubricas do Ativo (Disponibilidades, Aplicações Interfinanceiras e TVM e Derivativos) sobre o Ativo Total a cada período, seguindo Oliveira, Schiozer e Barros (2015). Uma limitação do uso dessa variável é que a liquidez dos ativos é uma proxy imperfeita para a situação de liquidez do banco, que depende também das características dos passivos bancários. Em outras palavras, essa variável mede a liquidez do banco com erro. Do ponto de vista da estimação econométrica, isso seria um problema maior se o erro de medida fosse sistematicamente correlacionado com as demais variáveis. Não temos nenhuma razão para acreditar que isso ocorra em nosso estudo.

- Crédito/Ativo Total (Créd/AT): ao contrário do observado nos bancos dos EUA, a participação do crédito nos ativos variou substancialmente ao longo de nosso período amostral, e de maneira heterogênea entre os bancos.

Uma possível alternativa nas estimações seria utilizar os Ativos Ponderados pelo Risco (APR), que capturam simultaneamente variações no volume de ativos de um banco e variações no risco dos ativos (via mudança dos fatores de ponderação de risco de crédito, ou mudança nas exposições a riscos de mercado e/ou operacional). Nossas especificações (principal e de robustez) procuram capturar cada um desses fatores de maneira distinta.

O capital alvo estimado, ou $\hat{k}_{\text {alvo } i, t}$, é dado por:

$\hat{k}_{\text {alvo } i, t}=\left(\widehat{\alpha}_{\imath}+\hat{\theta} \boldsymbol{X}_{i, t-1}\right) / \lambda$ 
Onde $\widehat{\alpha}_{l}, \lambda$ e $\hat{\theta}$ são estimados pela regressão (Eq. 5); e $\boldsymbol{X}_{i, t-1}$ é o vetor descrito acima. A partir da estimação do capital alvo, $\hat{k}_{\text {alvo } i, t}$, o capital excedente é estimado por:

$$
\text { Capital } \widehat{\text { Excedente }}{ }_{i, t}=\frac{k_{i, t}-\hat{k}_{\text {alvo } i, t}}{\hat{k}_{\text {alvo } i, t}}
$$

Onde $k_{i, t}$ é o índice de capital observado no banco $i$ no momento $t$; e $\widehat{k}_{\text {alvo } i, t}$ é o índice de capital alvo estimado para o banco $i$ em $t$, calculado pela Equação 6 .

\section{Relação entre capital excedente e crédito concedido}

Na segunda etapa, estima-se a relação entre capital excedente e crédito livre. A variável dependente é a variação no volume de crédito livre, medida através da diferença entre os logaritmos naturais do volume de crédito concedido a partir de recursos livres (isto é, não direcionado) entre os períodos $t$ e $t$ - 1 . Esta etapa também segue Berrospide e Edge (2010), com adaptações. O controle da sazonalidade, assim como um ajuste à demanda, é realizado pela inclusão de quatro defasagens da variável dependente. A relação entre capital e crédito é capturada pelo coeficiente $\beta_{1}$ na equação 8:

$$
\begin{aligned}
& \Delta \text { lnCrédito }_{i, t}=\alpha_{0}+\alpha_{i}+\sum_{s=1}^{4} \gamma_{s} \Delta \text { lnCrédito }_{i, t-s}+\beta_{1} \text { Capıtal Excedente }_{i, t-1}+
\end{aligned}
$$

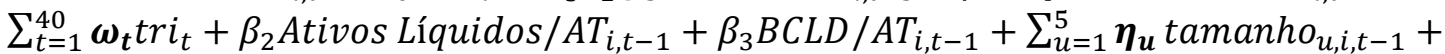

$$
\begin{aligned}
& \beta_{4} R O A_{i, t-1}+\beta_{5} R O A_{i, t-1}^{2}+d_{1} \text { Regulação }_{i, t-1}
\end{aligned}
$$

Onde $\Delta \operatorname{lnCrédito~}{ }_{i, t}$ é o crescimento do crédito livre, calculado como a variação do logaritmo natural do volume de crédito livre de cada banco $i$ entre os períodos $t$ e $t-1$; Capıtal Excedente ${ }_{i, t-1}$ é estimado conforme a equação 7 ; tri $i_{t}$ Ativos Líquidos $/ A T_{i, t-1} ; B C L D / A T_{i, t-1} ;$ tamanho $_{u, i, t-1}$; $R O A_{i, t-1} ; R O A_{i, t-1}^{2}$; Regulação $o_{i, t-1}$ são definidos conforme subseção anterior; $\alpha_{0}$ é a constante; $\alpha_{i}$ são efeitos fixos por banco $i ; \beta_{1}, \beta_{2}, \beta_{3}, \beta_{4}, \beta_{5}$ e $d_{1}$ são coeficientes; e $\boldsymbol{\gamma}_{\boldsymbol{s}}, \boldsymbol{\omega}_{\boldsymbol{t}}$ e $\boldsymbol{\eta}_{\boldsymbol{u}}$ são vetores a serem estimados. As variáveis foram winsorizadas em $1 \%$ a fim de tratar outliers ${ }^{(2)}$.

O coeficiente de interesse $\beta_{1}$ (da variável Capıta $\widehat{E x C} e d e n t e_{i, t-1}$ ) é menos suscetível a um viés por endogeneidade do que o dos índices observáveis de capital, uma vez que uma eventual relação simultânea entre capital e crédito estaria capturada na estimação do capital alvo. O capital excedente captura a parcela de variação exógena do capital; e a eventual influência do crédito no capital está capturada na estimativa de capital alvo.

Entretanto, se o modelo para estimativa do capital alvo for mal especificado, a regressão que relaciona capital excedente e crédito é questionável. Por esse motivo, em especificações alternativas de robustez, utilizam-se índices observáveis de capital em substituição ao capital excedente estimado: (a) o Patrimônio Líquido dividido pelo Ativo Total $(P L / A T)_{i, t-1}$; (b) o índice de Basileia $\left(I B_{i, t-1}\right)$; (c) o crescimento do Patrimônio Líquido, dado pela variação do logaritmo natural do Patrimônio Líquido do banco entre $t$ e $t-1\left(\Delta P L_{i, t}\right)$.

Para mitigar eventuais problemas de endogeneidade, as variáveis explicativas são todas defasadas. As dummies de trimestre foram incluídas para tratar sazonalidade, controlar efeitos de demanda sobre o crédito e tratar eventual efeito da endogeneidade ${ }^{(3)}$.

Finalmente, consideramos a possibilidade de alteração da relação entre capital e crédito durante o período amostral. As características macroeconômicas e institucionais do Brasil sofreram modificações importantes ao longo do período em análise. Na primeira parte do período amostral (de março de 2003 a junho de 2008), o crédito como porcentagem do PIB era consideravelmente menor do que na segunda parte (de setembro de 2008 a dezembro de 2012), quando passou a ser atividade principal de um número maior de bancos no sistema financeiro. A primeira parte do período amostral também se caracterizou por uma grande liquidez global, normalmente associada a um custo de oportunidade de capital mais baixo e, portanto, menor restrição para obter capital, ao contrário do segundo período, em que a crise diminui a liquidez global. Adicionalmente, as medidas macroprudenciais adotadas no 
segundo período passaram a exigir maior alocação de capital para certas modalidades de crédito. Todas estas características devem aumentar a sensibilidade do crédito em relação ao capital no segundo período da amostra. Assim, a análise foi feita distinguindo-se esses dois períodos.

\section{Bancos públicos}

A segunda hipótese do trabalho analisa se as relações entre o capital excedente e o crescimento do crédito são distintas entre bancos públicos e privados. As restrições de capital em bancos públicos tendem a ser menores do que em bancos privados. Além disso, o governo federal adotou uma política explícita para o crescimento do crédito nos bancos estatais, em especial após a crise financeira do final de 2008, sugerindo que os bancos públicos pudessem ser mais tolerantes, no curto prazo, quanto a desvios em relação ao índice de capital alvo. Em outras palavras, dada uma necessidade de ampliação exógena da carteira de crédito no curto prazo, esses bancos admitem que a capitalização possa ser feita em velocidade inferior à do crescimento do crédito.

Hipótese 2: A sensibilidade do crescimento do crédito ao capital é menor nos bancos públicos do que nos privados.

Para o teste da Hipótese 2, utiliza-se a mesma equação 8 incluindo uma dummy para banco público em interação com o capital excedente (e, nos testes de robustez, com as variáveis observáveis de capital: Patrimônio Líquido sobre Ativo Total e índice de Basileia).

\section{Dados e Panorama do Crédito no Brasil}

As fontes de dados são três: (a) balancetes trimestrais dos bancos, conforme o Plano Contábil das Instituições do Sistema Financeiro Nacional (Cosif); (b) informações sobre o crédito originado com recursos livres proveniente do Sistema de Informações de Crédito do Banco Central do Brasil (SCR) (documento 3040) ${ }^{(4)} \mathrm{e}$ (c) demonstrações financeiras publicadas no relatório público TOP50 do Banco Central do Brasil (Bacen).

O período considerado foi de 2003 a 2012, totalizando 40 trimestres. O período amostral é suficientemente amplo, tendo número de observações que permite modelar as regressões propostas, e abrangendo um ciclo econômico completo, com períodos de expansão e contração, incluindo uma crise financeira internacional, mas sem alterações significantes no ambiente político e institucional.

A base de dados cobre os segmentos bancários I e II que possuíam carteira de crédito. O segmento bancário I é composto por bancos comerciais, bancos múltiplos com carteira comercial ou Caixa Econômica; ou por conglomerado composto por pelo menos uma instituição deste tipo. O segmento bancário II é composto por bancos múltiplos sem carteira comercial e por bancos de investimento; ou por conglomerado composto por pelo menos uma instituição deste tipo que não façam parte do segmento I. Os segmentos III e IV não foram incluídos na amostra por se entender que as instituições pertencentes a estes segmentos possuem características e normas específicas que descaracterizariam o estudo: o segmento III contém as cooperativas de crédito e o segmento IV é referente a bancos de desenvolvimento que não integram conglomerado. Não foram consideradas as demais instituições financeiras não bancárias (consórcios, corretoras, empresas de cartões de crédito, etc.). Por simplicidade, as instituições financeiras e os conglomerados que compõem a base de dados são simplesmente denominados bancos.

\section{Panorama do capital bancário e do crédito no Brasil}

A Figura 1 apresenta a evolução da proporção das operações de crédito no Ativo dos bancos da amostra ao longo do período analisado. Nota-se um crescimento consistente dessa proporção: a participação do crédito no Ativo subiu de 40\% em março de 2003 para 51\% no final de 2012. Quando apenas os bancos públicos são considerados, um aumento ainda maior da participação se verifica: de 
30,6\% em março de 2003 para 55\% em dezembro de 2012. A proporção de crédito livre no total do crédito se manteve em torno de $70 \%$ na amostra completa, e em torno de 55\% nos bancos públicos.

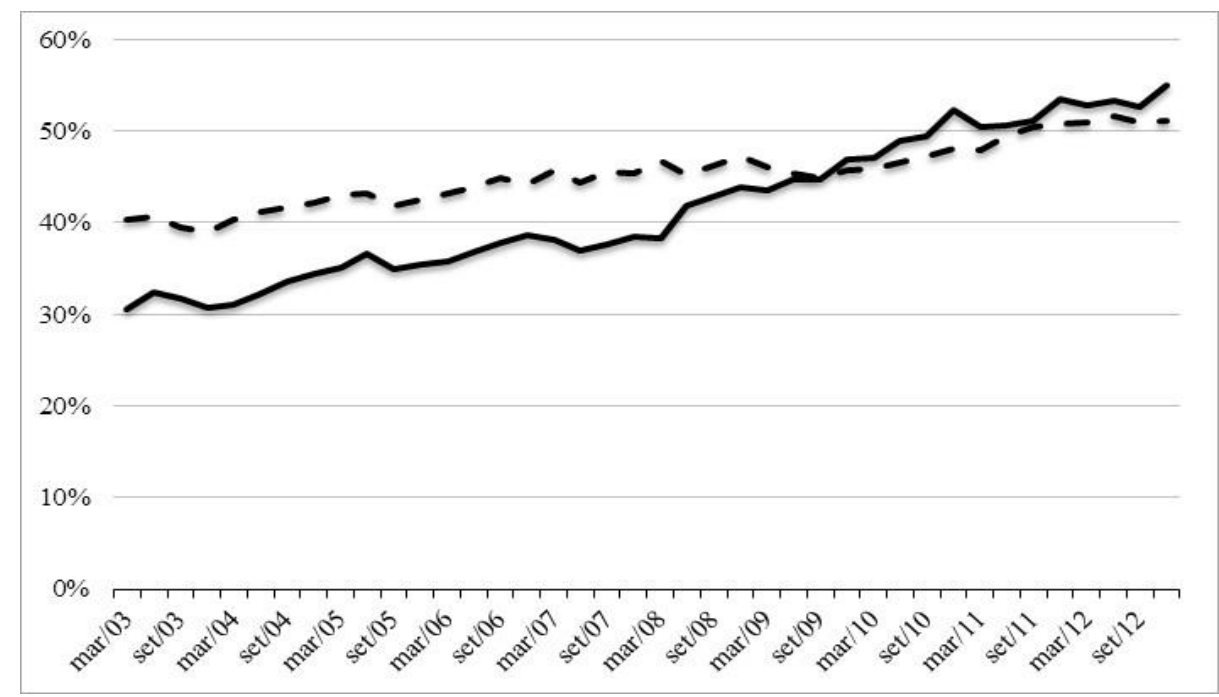

Figura 1. Evolução da Participação do Crédito do nos Ativos dos Bancos

O gráfico apresenta a participação agregada das operações de crédito no Ativo Total. A linha tracejada considera todos os bancos. A linha contínua considera apenas os bancos públicos. Fonte: construído pelos autores a partir de Banco Central do Brasil. (n.d.). 50 maiores bancos $e$ o consolidado do Sistema Financeiro Nacional. Recuperado de www4.bcb.gov.br/top50/port/top50.asp

A Figura 2 mostra que o volume de crédito originado a partir de recursos livres é crescente ao longo do período analisado, apresentando um aumento de mais de cinco vezes em 10 anos (de quase R\$ 230 bilhões para quase $\mathrm{R} \$ 1,4$ trilhão). Considerando apenas os bancos públicos, o volume de crédito livre também é crescente, apresentando um aumento de quase 7,5 vezes, de $\mathrm{R} \$ 51$ bilhões para $\mathrm{R} \$ 432$ bilhões. No mesmo período, o Patrimônio Líquido agregado (todos os bancos) apresentou aumento um pouco mais modesto do que o crescimento do crédito livre, de aproximadamente 3,5 vezes (de cerca de $\mathrm{R} \$ 90$ bilhões para mais de $\mathrm{R} \$ 410$ bilhões), ao passo que nos bancos públicos o aumento do Patrimônio Líquido foi de aproximadamente quatro vezes (de quase R \$ 20 bilhões para mais de R \$99,5 bilhões).

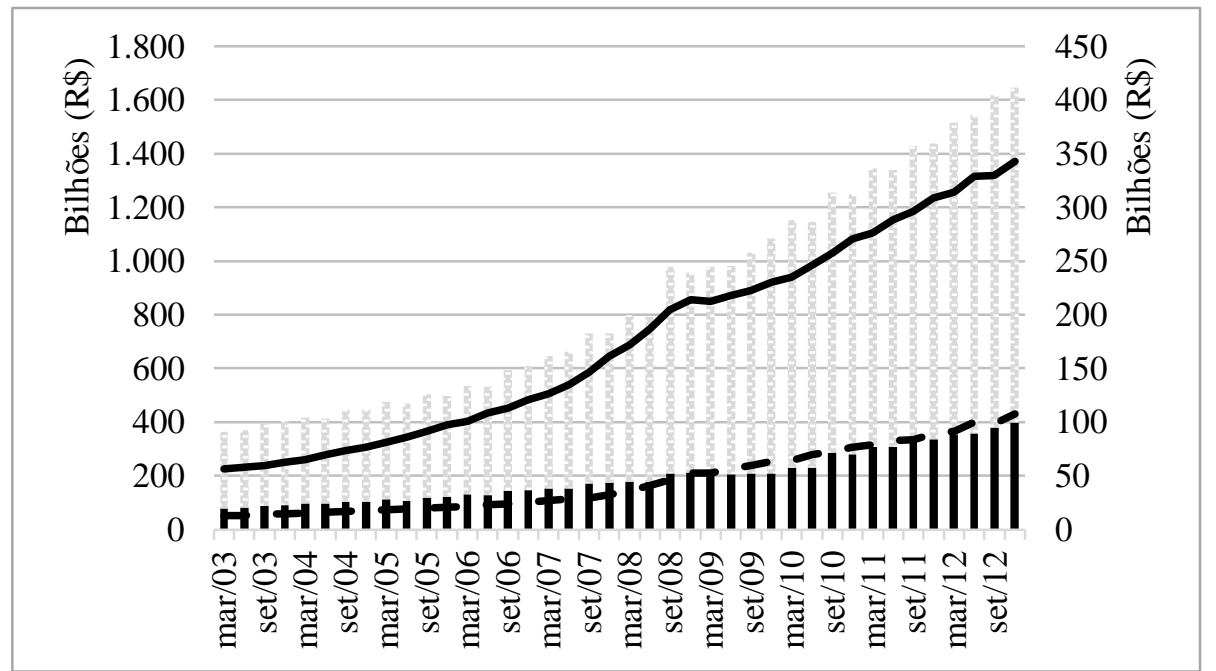

Figura 2. Volume de Crédito e Patrimônio Líquido ao Longo do Tempo

O gráfico apresenta a evolução do somatório do volume de crédito livre. A linha contínua mostra os valores para todas as instituições consideradas, e a linha tracejada mostra a mesma medida para os bancos públicos (ambas com escala à esquerda). A evolução do Patrimônio Líquido agregado da totalidade das instituições é mostrada pelas barras empilhadas. A barra sólida (menor) corresponde ao Patrimônio Líquido dos bancos públicos e as barras com textura, ao dos bancos privados (ambas com escala à direita). Fonte: elaborado pelos autores a partir de dados de Banco Central do Brasil. (n.d.). 50 maiores bancos $e o$ consolidado do Sistema Financeiro Nacional. Recuperado de www4.bcb.gov.br/top50/port/top50.asp e de Banco Central do Brasil. (2002). SCR - Sistema de Informações de Crédito. Base de dados. Brasília: Autor. 
A Figura 3 sugere alteração na relação Crédito livre/Patrimônio Líquido ao longo do tempo (a linha contínua mostra os valores observados para toda a amostra; e a linha tracejada, os valores para os bancos públicos). Quando considerados todos os bancos, o crédito cresceu mais que o Patrimônio Líquido no período de março de 2003 a junho de 2008. O índice de crédito livre sobre Patrimônio Líquido passou de 2,47 em março de 2003 para 3,77 em junho de 2008. A partir de setembro de 2008, a relação se mantém relativamente estável, em aproximadamente 3,4. A crise financeira global e uma maior preocupação com relação ao risco e a liquidez dos ativos (por parte do mercado e dos reguladores) podem ter modificado o padrão da substituição de ativos. Assim, distinguem-se dois períodos: o primeiro (anterior à quebra do Lehman Brothers) caracterizado pelo crescimento do quociente crédito sobre Patrimônio Líquido; e o segundo caracterizado apenas por flutuações sazonais sobre o quociente. Nos bancos públicos, o crescimento da relação Crédito Livre/Patrimônio Líquido se mantém por mais tempo, até dezembro de 2009, crescendo de 2,57 (em março de 2003) para 4,83 (em dezembro de 2009). A partir de setembro de 2010, a relação se mantém relativamente estável, em aproximadamente 4,2.

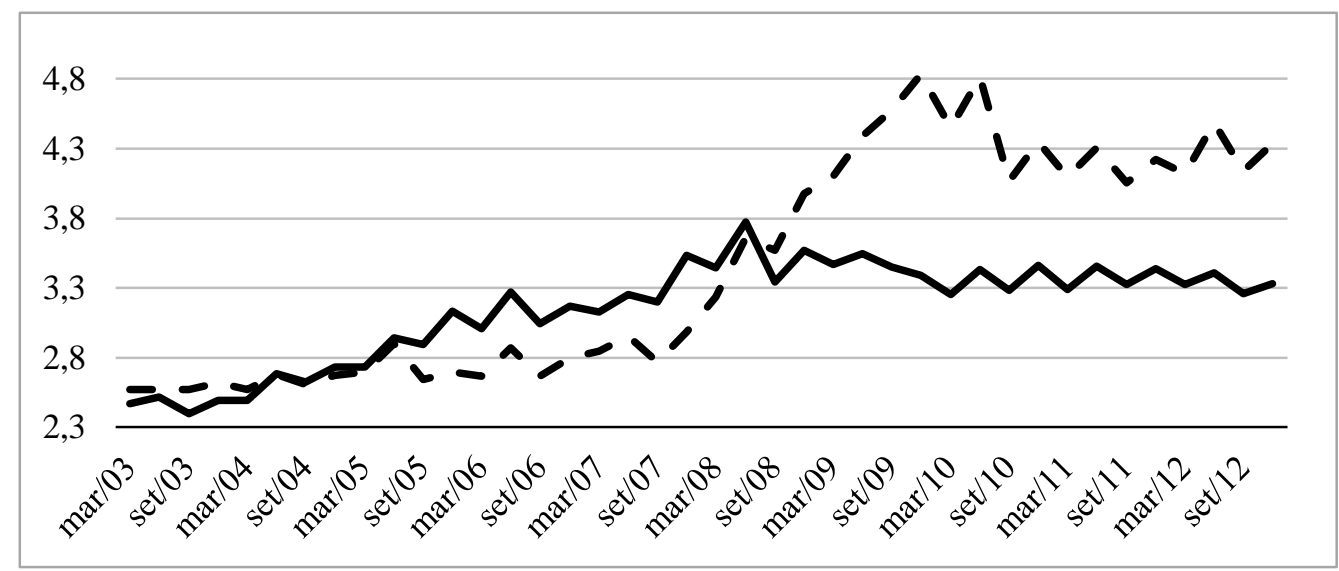

Figura 3. Relação entre Crédito e Patrimônio Líquido

O gráfico apresenta a evolução do quociente entre crédito originado a partir de recursos livres e o Patrimônio Líquido. A linha contínua mostra o valor para a totalidade de bancos, e a linha tracejada para os bancos públicos. Fonte: elaborado pelos autores a partir de dados de Banco Central do Brasil. (n.d.). 50 maiores bancos e o consolidado do Sistema Financeiro Nacional. Recuperado de www4.bcb.gov.br/top50/port/top50.asp e de Banco Central do Brasil. (2002). SCR - Sistema de Informações de Crédito. Base de dados. Brasília: Autor.

Em linha com a tese de alteração da associação entre capital e crédito ao longo do tempo, a Figura 3 sugere que o capital não representou restrição ao crescimento do crédito na primeira parte do período amostral, mas passou a representar restrição efetiva ao crescimento do crédito após a crise do subprime e a diminuição da liquidez econômica global.

\section{Estatísticas descritivas}

Para as análises subsequentes, são excluídas as observações de bancos em regime especial ou sob intervenção do Banco Central, bancos que não concederam crédito livre durante o período amostral, bancos cujo quociente médio de crédito livre sobre Ativo Total é menor que 2,5\% e que não apresentaram quociente maior que $3 \%$ em nenhum trimestre; o primeiro ano de um novo banco (quando não originário de alguma transformação societária); e bancos com menos de nove observações em trimestre consecutivos.

Foram considerados novos bancos: alterações de conglomerado para instituição financeira individual ou vice-versa com variação (positiva ou negativa) superior a $10 \%$ do Ativo Total; fusões e aquisições com variação superior a $10 \%$ do Ativo Total; bancos cujo crescimento do crédito está acima do percentil $99,5 \%$ e abaixo do percentil $0,5 \%$ na distribuição dessa variável. Os novos bancos originários de fusão ou aquisição tiveram as variáveis dos originadores somadas nos períodos antecedentes a fim de não perder observações (o índice de Basileia foi ponderado pelo Ativo Total). Após todas as exclusões, a amostra final resultou em 4.471 observações e 143 bancos, sendo 14 públicos e 129 privados. 
A Tabela 1 apresenta as estatísticas das principais variáveis utilizadas no estudo. A primeira coluna apresenta os indicadores para todo o período; a segunda coluna apresenta os indicadores para o período de março de 2003 a junho de 2008; e a terceira coluna, para o período de setembro de 2008 a dezembro de 2012. As estatísticas mostram que há diferenças importantes entre o primeiro e o segundo período. Comparado ao segundo período, o primeiro caracteriza-se por apresentar menores ativos $(\ln \mathrm{AT})$; maiores retornos (ROA); maiores índices de Basileia (Basileia); menores participações do crédito no Ativo Total (Créd/AT); e maiores participações dos Ativos Líquidos no Ativo Total.

Tabela 1

Estatística Descritiva das Variáveis Utilizadas para a Estimativa do Índice de Capital Alvo

\begin{tabular}{|c|c|c|c|c|}
\hline Variável & Indicador & Mar/2003 a Dez/2012 & Mar/2003 a Jun/2008 & Set/2008 a Dez/2012 \\
\hline \multirow[t]{3}{*}{$\Delta \%$ Crédito Livre } & Média & 0,0535 & 0,0726 & 0,0305 \\
\hline & Mediana & 0,0467 & 0,0596 & 0,0320 \\
\hline & Desvio-padrão & 0,2153 & 0,2233 & 0,2030 \\
\hline \multirow[t]{3}{*}{ PL/AT } & Média & 0,2109 & 0,2143 & 0,2066 \\
\hline & Mediana & 0,1500 & 0,1499 & 0,1501 \\
\hline & Desvio-padrão & 0,1901 & 0,1941 & 0,1849 \\
\hline \multirow[t]{3}{*}{ Basileia } & Média & 0,3478 & 0,3631 & 0,3286 \\
\hline & Mediana & 0,1940 & 0,2092 & 0,1810 \\
\hline & Desvio-padrão & 0,6731 & 0,7281 & 0,5963 \\
\hline \multirow[t]{3}{*}{$\Delta \mathrm{PL}$} & Média & 0,0344 & 0,0405 & 0,0270 \\
\hline & Mediana & 0,0041 & 0,0077 & 0,0012 \\
\hline & Desvio-padrão & 0,1295 & 0,1338 & 0,1237 \\
\hline \multirow[t]{3}{*}{$\ln \mathrm{AT}$} & Média & 21,2261 & 20,9686 & 21,5501 \\
\hline & Mediana & 21,2103 & 20,9282 & 21,5555 \\
\hline & Desvio-padrão & 2,1736 & 2,0949 & 2,2273 \\
\hline \multirow{3}{*}{ ROA } & Média & 0,0041 & 0,0058 & 0,0020 \\
\hline & Mediana & 0,0040 & 0,0052 & 0,0031 \\
\hline & Desvio-padrão & 0,0180 & 0,0165 & 0,0194 \\
\hline \multirow[t]{3}{*}{ BCLD/AT } & Média & 0,0777 & 0,0812 & 0,0733 \\
\hline & Mediana & 0,0342 & 0,0340 & 0,0343 \\
\hline & Desvio-padrão & 0,1388 & 0,1324 & 0,1464 \\
\hline \multirow[t]{3}{*}{ Créd/AT } & Média & 0,5259 & 0,5084 & 0,5478 \\
\hline & Mediana & 0,5282 & 0,5082 & 0,5450 \\
\hline & Desvio-padrão & 0,2325 & 0,2333 & 0,2297 \\
\hline \multirow[t]{3}{*}{ Ativos Líquidos } & Média & 0,3854 & 0,3997 & 0,3674 \\
\hline & Mediana & 0,3661 & 0,3866 & 0,3444 \\
\hline & Desvio-padrão & 0,2319 & 0,2395 & 0,2207 \\
\hline
\end{tabular}

Nota. $\Delta$ lnCrédito Livre é a variação no logaritmo natural do Crédito Livre; PL/AT é Patrimônio Líquido dividido pelo Ativo Total; Basileia é o índice de Basileia; $\triangle \mathrm{PL}$ é a variação no logaritmo natural do Patrimônio Líquido; lnAT é o logaritmo natural do Ativo Total; ROA é Lucro Líquido dividido pelo Ativo Total; BCLD/AT é Baixa de Crédito de Liquidação Duvidosa dividida pelo Ativo Total; Créd/AT é o crédito sobre Ativo Total; Ativos Líquidos é a soma de Disponibilidades, Aplicações Interfinanceiras e TVM e instrumentos financeiros derivativos sobre Ativo Total. Fonte: elaborado pelos autores, a partir de dados primários de Banco Central do Brasil. (n.d.). 50 maiores bancos e o consolidado do Sistema Financeiro Nacional. Recuperado de www4.bcb.gov.br/top50/port/top50.asp e de Banco Central do Brasil. (2002). SCR - Sistema de Informações de Crédito. Base de dados. Brasília: Autor. 


\section{Resultados}

\section{Estimação do capital alvo e do capital excedente}

O modelo para cálculo do capital alvo segue as equações 5 e 6 . A estimação é realizada pelo método de Mínimos Quadrados Ordinários com efeito fixos (Ordinary Least Square, FE [OLS FE]) e não considera as participações do crédito e dos ativos líquidos sobre o Ativo Total. Para corrigir o efeito da autocorrelação no cômputo dos erros padrão, utiliza o desvio padrão agrupado (clustered) por banco (Stock \& Watson, 2008).

Uma preocupação referente à estimação por efeitos fixos é que a presença da variável defasada possa causar uma inconsistência no estimador ${ }^{(5)}$. Como teste de robustez, a equação 5 também é estimada pelo método Mínimos Quadrados Ordinários com efeitos fixos e autocorrelação de primeira ordem (OLS FE com AR(1)) e pelo método Feasible Generalized Least-Square [FGLS] ${ }^{(6)}$. Nessas estimações, os coeficientes não sofrem alteração substancial em relação ao modelo OLS FE.

Finalmente, incluem-se como variáveis de controle as participações do crédito e dos ativos líquidos sobre o Ativo Total para as estimações feitas com os três diferentes métodos. Mais uma vez, os resultados não sofrem alterações relevantes. Os resultados dessas estimações são omitidos para salvar espaço e estão disponíveis sob requisição aos autores.

A Tabela 2 apresenta as estatísticas descritivas do índice de capital (PL/AT) observado e das estimativas do índice de capital alvo conforme os três métodos de estimação. As estatísticas referentes ao índice de capital alvo calculado através de OLS FE e FGLS são bastante próximas entre si; já as estatísticas geradas pelo método OLS FE AR(1) são um pouco menores.

Tabela 2

Estatística Descritiva do Patrimônio Líquido sobre Ativo Total; e da Estimativa do Índice de Capital Alvo

\begin{tabular}{lccccc}
\hline & Média & $\mathbf{1}^{\circ}$ quartil & Mediana & $\mathbf{3}^{\circ}$ quartil & Desvio padrão \\
\hline PL/AT & 0,2109 & 0,0961 & 0,1500 & 0,2474 & 0,1901 \\
K-alvo OLS FE & 0,2001 & 0,0952 & 0,1546 & 0,2390 & 0,1688 \\
K-alvo OLS FE AR(1) & 0,1913 & 0,0873 & 0,1472 & 0,2289 & 0,1683 \\
K-alvo FGLS & 0,2016 & 0,0975 & 0,1560 & 0,2398 & 0,1687 \\
\hline
\end{tabular}

Nota. PL/AT é Patrimônio Líquido dividido pelo Ativo Total, ou capital; K-alvo é o índice de capital alvo. Fonte: elaborado pelos autores.

As estatísticas das estimativas de capital alvo aproximam-se das estimativas do indicador de capital observável (PL/AT), mas com um desvio padrão menor. Esse resultado é congruente com a hipótese de capital alvo ativamente gerenciado, pois o capital alvo se constitui como parâmetro de longo prazo, com menor volatilidade. Doravante, todas as menções ao capital alvo e capital excedente se referem aos valores estimados por OLS FE. A escolha desta especificação se justifica pela maior simplicidade dos pressupostos (ao mesmo tempo em que mantém estimativas próximas às geradas por FGLS) e pela maior robustez do método na presença de variável dependente defasada (Kristensen \& Wawro, 2003). As especificações com as variáveis de controle Ativos Líquidos/Ativo Total e Crédito/Ativo Total retornam resultados compatíveis com os da especificação principal (resultados não reportados). 
A Figura 4 apresenta, na linha contínua, a evolução ao longo do tempo da soma do Patrimônio Líquido sobre o Ativo Total de todos os bancos da amostra; e na linha tracejada, a evolução da soma do capital alvo estimado dividido pelo Ativo Total, também para todos os bancos da amostra. Além da menor volatilidade do capital alvo, nota-se que este é inferior ao Patrimônio Líquido observado na maior parte do tempo entre junho de 2003 a junho de 2008. No período posterior, o padrão se inverte, com o capital alvo total superando o Patrimônio Líquido observado na maior parte do tempo. O resultado está em linha com a evolução da relação entre o crédito e o Patrimônio Líquido, apresentada na Figura 3, caracterizando períodos distintos. No primeiro período, a liquidez dos mercados, a menor restrição de capital e o otimismo com relação ao cenário econômico podem responder pela maior tolerância a uma deficiência de capital em relação ao alvo. No segundo período, a situação se inverte: dada a maior restrição de capital, adota-se uma política de capital mais conservadora.

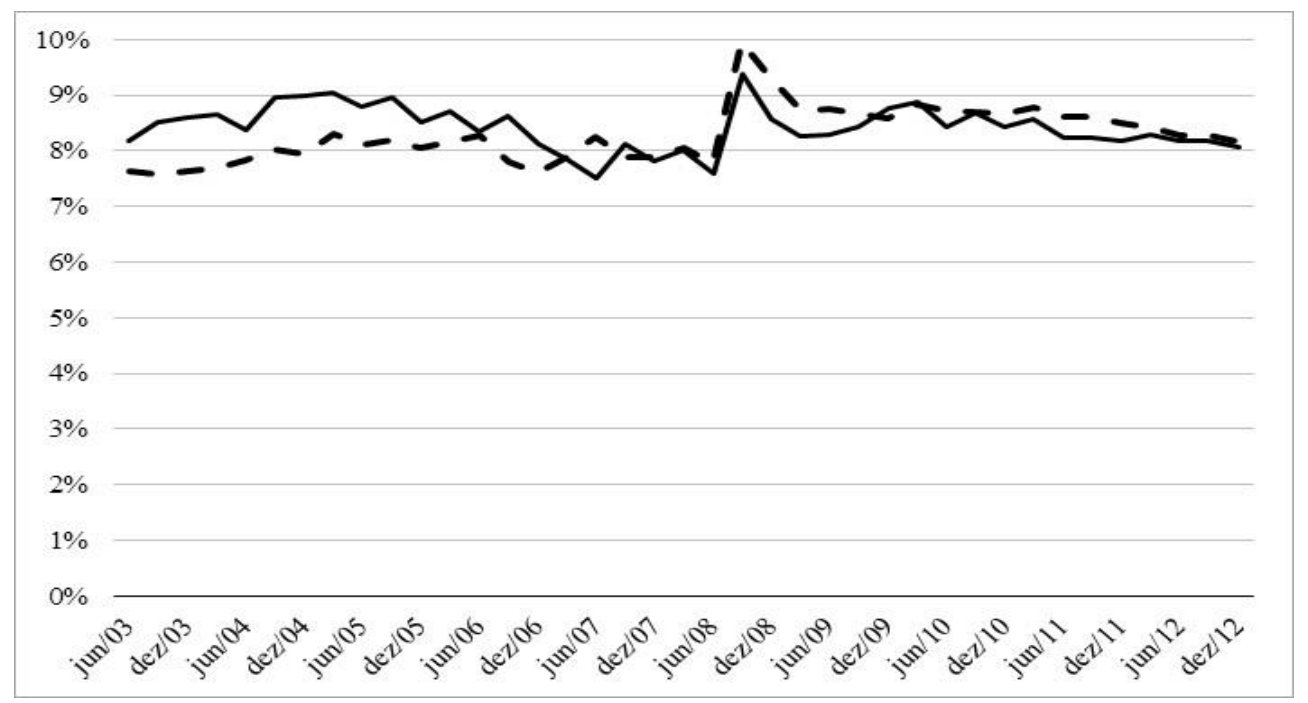

Figura 4. Patrimônio Líquido sobre Ativo Total (PL/AT) e Capital Alvo (K-alvo)

O gráfico apresenta a evolução (ao longo do tempo) do Patrimônio Líquido sobre Ativo Total (linha contínua) considerando a amostra construída; e Capital Alvo calculado via OLS FE (linha tracejada). Fonte: elaborado pelos autores conforme corte e metodologia apresentados.

A média do capital excedente estimado é de $6,77 \%$, o que significa que os bancos mantêm, em média, um índice de capital (PL/AT) 6,77\% superior ao capital alvo. A mediana é menor, mas também positiva $(2,31 \%)$, e o desvio padrão é de $37,62 \%$.

\section{Relação entre o crescimento do crédito e o capital}

A Tabela 3 apresenta os resultados da regressão entre crescimento do crédito e capital excedente. As colunas (1) a (3) reportam os resultados de diferentes especificações para o primeiro período (de março de 2003 a junho de 2008), e as colunas (4) a (6) reportam respectivamente as mesmas especificações, mas para o segundo período (de setembro de 2008 a dezembro de 2012). Todas as regressões foram estimadas por OLS FE. Como em Berrospide e Edge (2010), foi utilizado um procedimento de bootstrap com 2.000 replicações a fim de estimar os erros-padrão sujeitos a viés de variável construída (capital excedente). 
Tabela 3

Relação entre Crédito e Capital Excedente

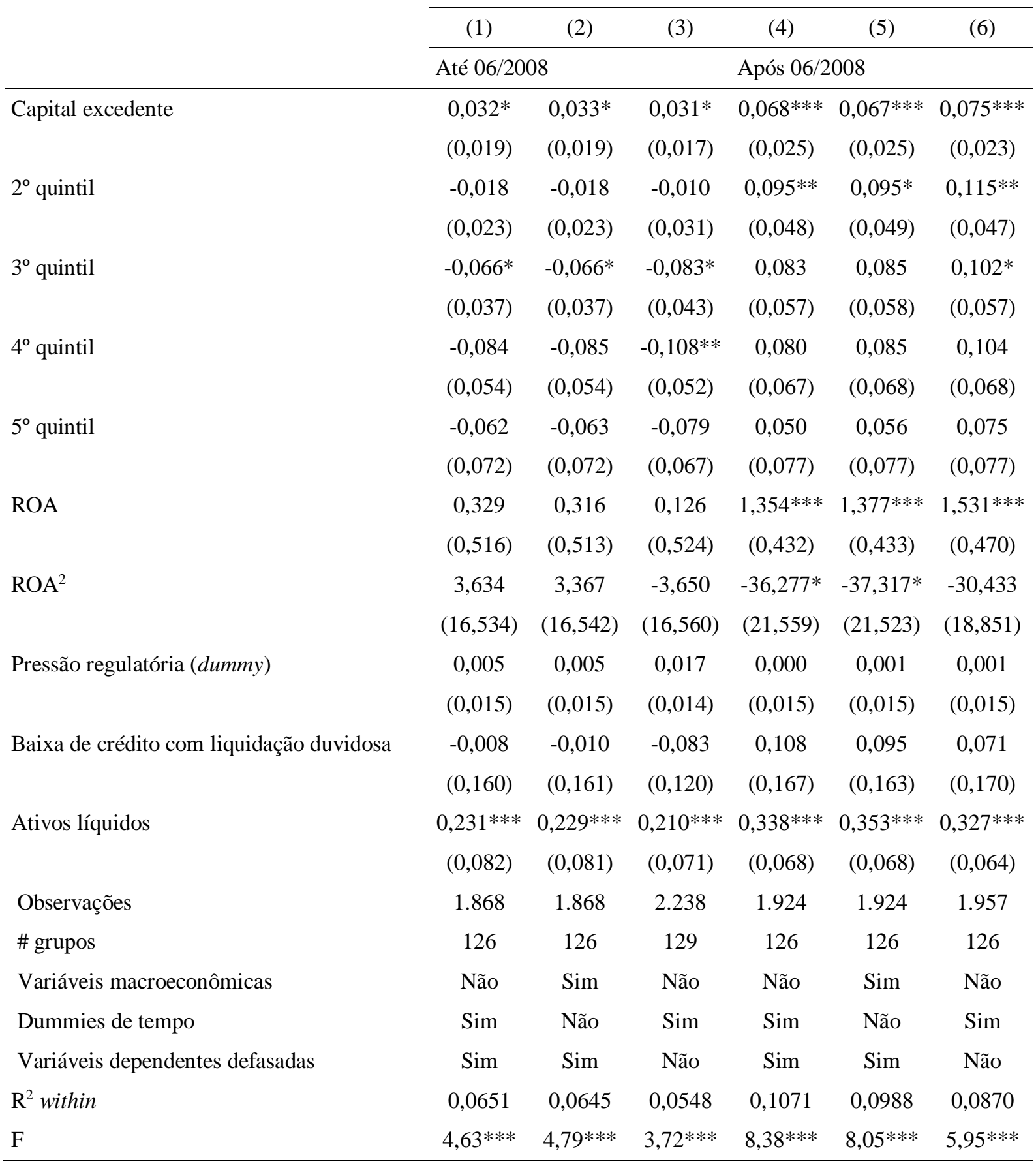

Nota. A variável dependente é o crescimento do crédito livre $\left(\Delta \operatorname{lnCrédito} o_{i, t}\right)$, calculado como a variação em logaritmo natural do volume de crédito livre do banco $i$, entre os momentos $t$ e $t$-1. As variáveis independentes são: capital excedente OLS FE, calculado conforme equação 1 ; dummies de tamanho ( $2^{\circ}$ quintil ao $5^{\circ}$ quintil); variáveis de ganhos ROA (Retorno sobre Ativos) e $\mathrm{ROA}^{2}$ (quadrado do Retorno sobre Ativos); dummy para pressão regulatória; Baixa de Crédito de Liquidação Duvidosa sobre o Ativo Total; e a participação de Ativos Líquidos no Ativo Total. Todas as variáveis independentes estão defasadas em um período. Todas as especificações foram realizadas através do método OLS FE. Foi utilizado um procedimento de bootstrap (com 2000 replicações) a fim de estimar os erros-padrão sujeitos a viés de variável construída. Fonte: elaborado pelos autores. Desvio padrão entre parênteses: $* * * p<0,01 ; * * p<0,05 ; * p<0,1$.

As colunas (1) e (4) mostram os resultados da especificação-base da equação 8 - isto é, incluindo dummies de tempo e defasagens da variável dependente. Os resultados indicam relação positiva entre o crescimento do crédito e o capital excedente. O coeficiente de interesse $\beta_{1}$ (da variável Capital 
Excedente) é de 0,032 para o período de março de 2003 a junho de 2008 (coluna (1)). Já no segundo período, é de 0,068 (coluna (4)), mais do que o dobro do estimado para o primeiro período, e estatisticamente mais significante. Ou seja, durante o primeiro período, um aumento de $1 \%$ no capital excedente associa-se a um crescimento de $0,032 \%$ na carteira de crédito livre no trimestre subsequente; já no segundo período, a mesma variação associa-se a um crescimento de $0,068 \%$ no crédito livre.

No primeiro período, considerando o capital alvo mediano (15,36\%), o acréscimo de um ponto percentual na relação PL/AT representa aumento de 6,51\% no capital excedente (dado por $[(16,36 \%-$ 15,36\%)/15,36\%]). Conforme a especificação 1, a variação de um ponto percentual de aumento no capital excedente está associada a $0,032 \%$ de aumento na carteira de crédito livre. Assim, o aumento de $6,51 \%$ associa-se a um aumento de apenas $0,21 \%$ na carteira (dado por $[(6,51 \% \times 0,032 \%) / 1 \%])$. Já no segundo período, a mesma variação associa-se a um aumento de $0,43 \%$ na carteira de crédito $^{(7)}$.

É possível estimar o efeito da variação de $\mathrm{R} \$ 1$ no capital sobre o crédito com o seguinte exercício, adaptado de Berrospide e Edge (2010). O crescimento relativo do crédito, $\left(L_{t}-L_{t-1}\right) / L_{t-1}$, é igual a $\beta_{1}$ vezes o capital excedente, ou seja $\left(L_{t}-L_{t-1}\right) / L_{t-1}=\beta_{1} \times\left(K_{t}-K_{t}^{*}\right) / K^{*}$. Rearranjando os termos e assumindo uma economia em estado estável, tem-se: $\left(L_{t}-L_{t-1}^{*}\right)=\beta_{1} \times L^{*} / A^{*} \times A^{*} / K^{*} \times$ $\left(K_{t}-K_{t}^{*}\right)$. Assumindo que: (a) o crescimento do crédito direcionado siga o crescimento do crédito livre; (b) a participação mediana do crédito no Ativo Total durante o primeiro período, $L^{*} / A^{*}$, é de $50,82 \%$ e (c) a relação entre Ativo Total e o capital alvo mediano, $A^{*} / K^{*}$, é de 6,51; então, a adição de $\mathrm{R} \$ 1$ ao capital alvo, associar-se-ia, coeteris paribus, ao acréscimo na carteira de crédito de $\mathrm{R} \$ 0,11$ no primeiro período de análise ${ }^{(8)}$. Exercício similar realizado para o segundo período produz uma associação de $\mathrm{R} \$ 0,24$ adicionais na carteira de crédito. O cálculo com a condição coeteris paribus é apenas uma aproximação do efeito real, uma vez que o índice de capitalização e a liquidez (entre outras variáveis) se alteram endogenamente, afetando as estimativas. Os valores em reais podem estar subestimados, uma vez que pode existir um efeito persistente ao longo dos trimestres subsequentes. Entretanto, as regressões indicam que tal efeito não afetaria tanto a magnitude da estimativa, já que os coeficientes das variáveis dependentes defasadas somam apenas 0,12 no primeiro período e 0,08 no segundo (resultados não reportados).

Caso não se considerasse um banco mediano, mas toda a amostra como se fosse um único banco, a adição de $\mathrm{R} \$ 1$ no capital alvo estaria associada, coeteris paribus, a um acréscimo na carteira de crédito de R $\$ 0,17$ em junho de 2008 e de R\$ 0,41 em dezembro de 2012. ${ }^{(9)}$ Mesmo admitindo alguma imprecisão nesses cálculos, percebe-se que a associação entre variações no capital e no crédito é modesta, e bastante inferior àquela obtida com a premissa de alavancagem constante e impossibilidade de ajuste no capital (que sugere uma variação de $\mathrm{R} \$ 10$ no crédito para uma mudança de $\mathrm{R}$ \$ 1 no capital).

Como teste de robustez, estimam-se as especificações mostradas das colunas (2) e (5) da Tabela 3, seguindo Berrospide e Edge (2010). Essas regressões incluem variáveis macroeconômicas (Índice Nacional de Preços ao Consumidor [IPCA], PIB e taxa Selic trimestrais) e dummies de trimestre no ano $\left(1^{\circ}, 2^{\circ}, 3^{\circ}\right.$ e $\left.4^{\circ}\right)$ em substituição às 40 dummies referentes aos trimestres na amostra. Os coeficientes de interesse são apenas marginalmente modificados, e os demais coeficientes não são substancialmente diferentes dos apresentados nas colunas (1) e (4). Em outro teste de robustez, as especificações das colunas (3) e (6) partem das especificações (1) e (4), respectivamente, mas retiram-se as variáveis dependentes defasadas, pois estas poderiam causar inconsistência nos estimadores (Angrist \& Pischke, 2009). Também neste caso, os coeficientes não são substancialmente alterados.

A participação dos Ativos Líquidos no Ativo Total, medida de liquidez, é positiva e estatisticamente significante a $1 \%$ para os dois períodos e em todas as especificações, como esperado. O coeficiente do ROA também é positivo e significante no segundo período, mas o seu quadrado também significante no segundo período, com exceção da especificação (6) - é negativo, evidenciando um efeito não linear (e marginalmente decrescente, quando positivo) do ROA sobre a variação do crédito. Para o banco médio do segundo período $(\operatorname{ROA}=2 \%$ ), um aumento de 0,1 ponto percentual no ROA está associado a um aumento esperado nos empréstimos livres de $([1,531-2 * 30,433 * 2 \%] *$ $0,1 \%$ ) $\approx 0,03 \%$ (o cálculo é feito utilizando o resultado da especificação 6 , já que nas outras especificações seria necessário calcular o efeito sobre a variável dependente defasada). A Baixa de 
Crédito com Liquidação Duvidosa, proxy do risco, e a dummy de pressão regulatória não são significantes em nenhuma das especificações. Não se nota monotonicidade (ou significância robusta) nas dummies de tamanho.

Todas as regressões da Tabela 3 foram re-estimadas substituindo o capital excedente calculado a partir da especificação OLS FE pelo capital excedente calculado a partir das especificações OLS FE $\operatorname{AR}(1)$ e FGLS (resultados não reportados). Os coeficientes $\beta_{1}$ dessas regressões são ligeiramente menores e menos significantes do que os reportados na Tabela 3, mas as inferências se mantêm qualitativamente inalteradas.

\section{Outros testes de robustez}

Uma preocupação sobre as inferências feitas até aqui sobre a relação entre capital excedente e crédito decorre do fato da variável capital excedente ser uma medida estimada (não observável). Erros de especificação poderiam tornar inconsistente a estimação da equação 8. Para mitigar essa preocupação, re-estimamos a equação 8 substituindo o capital excedente por índices observáveis de capital: Patrimônio Líquido sobre Ativo Total (PL/AT) e índice de Basileia (Basileia); e também pela variação em logaritmo do PL $(\triangle P L)$.

A Tabela 4 apresenta a especificação principal (com as dummies de tempo, sem as variáveis macroeconômicas e com as defasagens da variável dependente) substituindo a medida de capital excedente por: (a) PL/AT nas colunas (1) e (4); (b) Basileia nas colunas (2) e (5) e (c) $\Delta P L$ nas colunas (3) e (6). Todas as especificações foram estimadas pelo método OLS FE com erros-padrão robustos à heterocedasticidade.

Tabela 4

Relação do Crescimento do Crédito com PL/AT e com Basileia

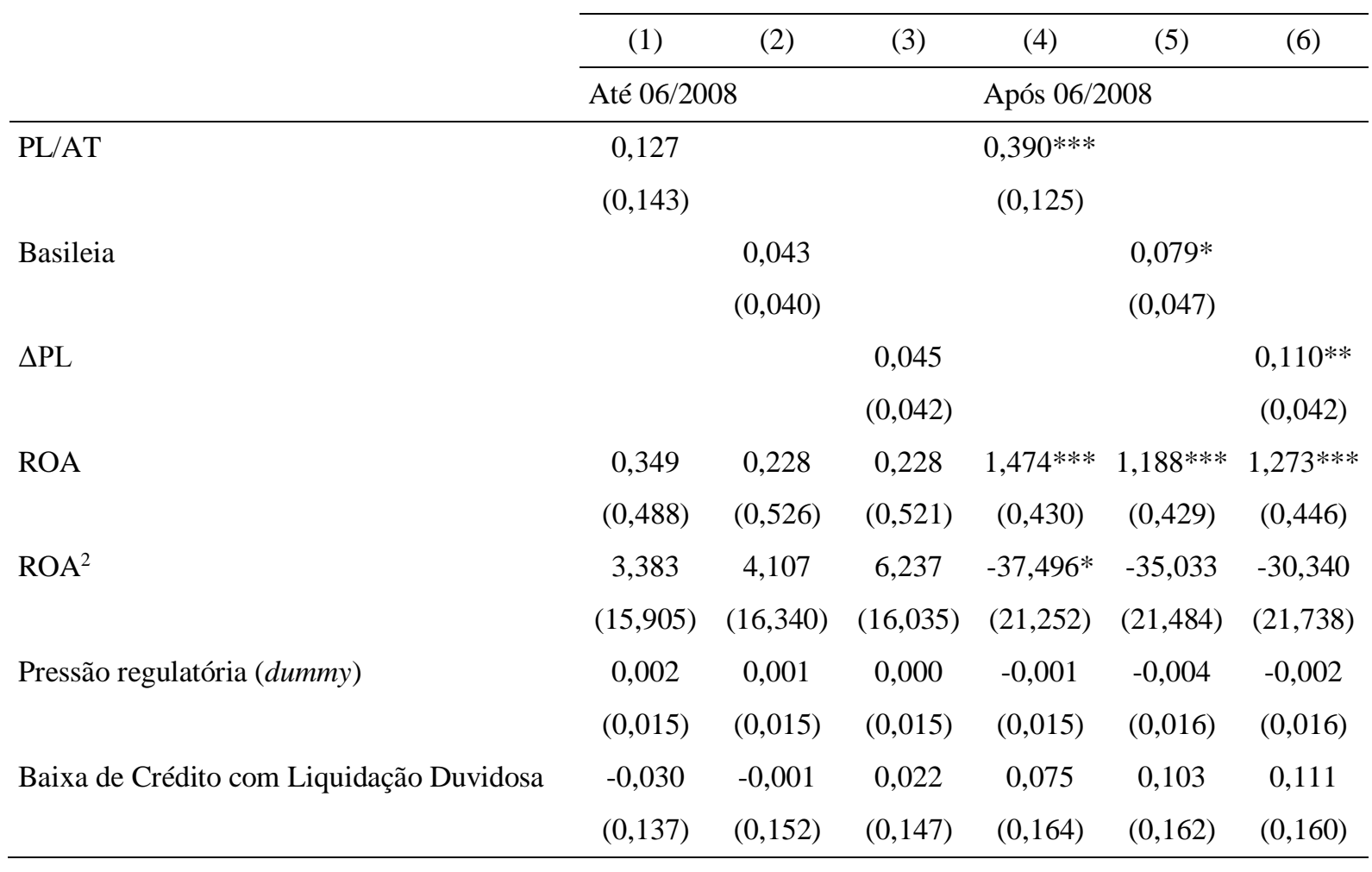


Tabela 4 (continuação)

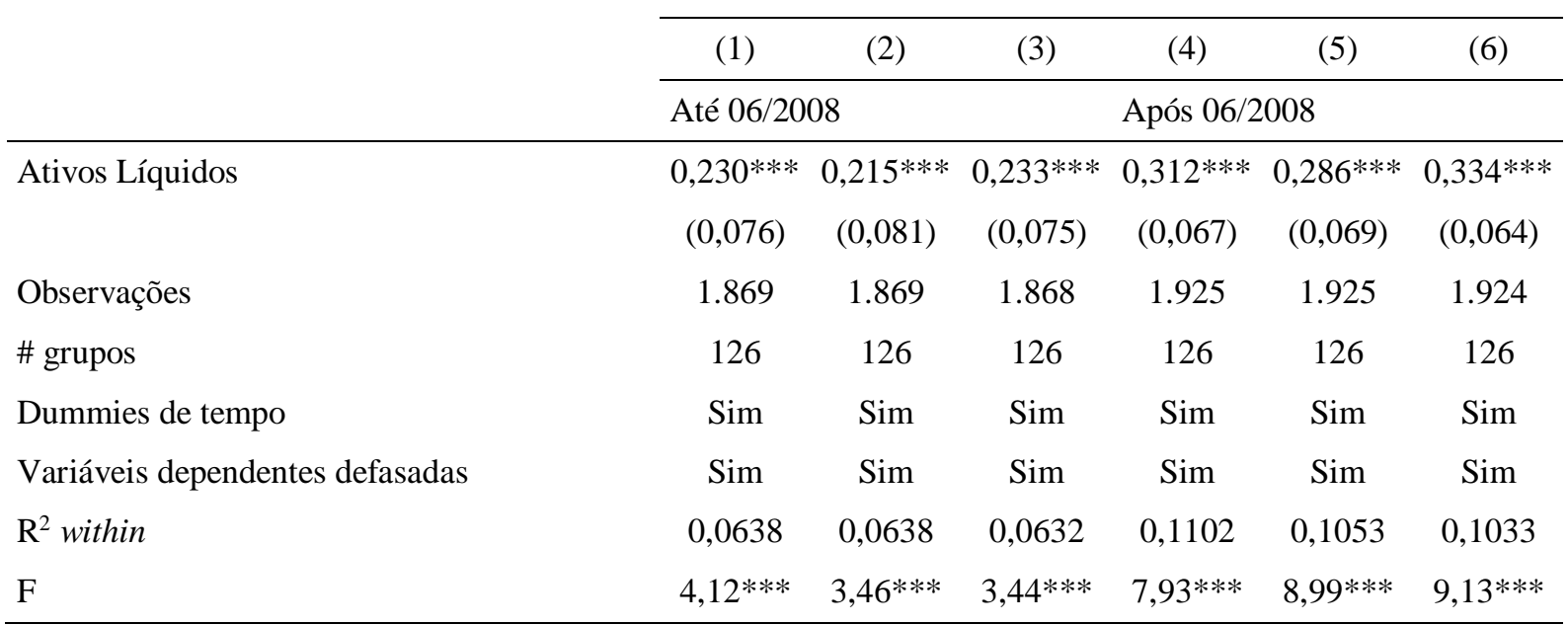

Nota. A variável dependente é o crescimento do crédito livre $\left(\Delta l n C r e ́ d i t o_{i, t}\right)$, calculado como a variação em logaritmo natural do volume de crédito livre do banco $i$, entre $t$ e $t-1$. As variáveis independentes são: Patrimônio Líquido sobre Ativo Total (PL/AT); índice de Basileia (Basileia); crescimento do Patrimônio Líquido ( $\Delta \mathrm{PL}$ ); dummies de tamanho (não reportadas); variáveis de ganhos ROA (Retorno sobre Ativos) e ROA² (quadrado do Retorno sobre Ativos); dummy para pressão regulatória; Baixa de Crédito de Liquidação Duvidosa sobre o Ativo Total; e a participação de Ativos Líquidos no Ativo Total. Todas as variáveis independentes estão defasadas em um período. Todas as especificações foram realizadas através do método OLS FE. Fonte: elaborado pelos autores.

Desvio padrão entre parênteses: ***p<0,01;**p<0,05; *p<0,1.

Os resultados corroboram a tese de alteração na relação entre o crescimento do crédito e o capital após junho de 2008: no primeiro período - colunas (1) a (3) - os coeficientes $\beta_{1}$ são positivos, mas não significantes, ao passo que, no segundo período - colunas (4) a (6) - os $\beta_{1}$ são maiores do que no primeiro período, e estatisticamente significantes.

O resultado da coluna (4) mostra que um incremento de 1 ponto percentual no PL/AT está associado a um aumento de $0,39 \%$ no crédito livre (significante a $1 \%$ ) no segundo período da amostra. Esse valor é bastante próximo daquele calculado anteriormente a partir do coeficiente do capital excedente para o banco mediano da amostra $(0,43 \%)$. O resultado mostrado na coluna (5) indica que um incremento de 1 ponto percentual no índice de Basileia está associado a um aumento de 0,079\% no crédito livre no trimestre subsequente (significante a 10\%), na segunda metade do período amostral. Finalmente, o resultado da coluna (6) mostra que um incremento de $1 \%$ no PL está associado a um aumento de $0,11 \%$ no crédito livre no trimestre subsequente (significante a 5\%), no segundo período amostral.

Os coeficientes das variáveis de controle não são substancialmente diferentes daqueles gerados para as especificações do capital excedente (Tabela 3). Apesar da interpretação econômica diferente que se deve dar aos coeficientes das variáveis de capital excedente e dos indicadores de capital observáveis, eles indicam robustez da equação 8. Em testes não reportados, as regressões com os indicadores observáveis de capital são também estimadas com as variáveis macroeconômicas em substituição às dummies de tempo, e também sem a presença das defasagens da variável dependente. Os resultados são similares.

Finalmente, a equação 8 foi estimada para duas subamostras distintas, compostas pelos bancos cuja relação Crédito/Ativo Total estivesse acima ou abaixo da mediana em cada período. Os resultados da Tabela 5 indicam que, para os bancos com maior participação de crédito nos ativos, os coeficientes que medem a sensibilidade do crédito ao capital no segundo período são ligeiramente superiores aos estimados para a amostra completa (cujos resultados estão nas Tabelas 3 e 4), especialmente para os indicadores diretamente observáveis de capital (Basileia e PL/AT). Analogamente, os resultados da Tabela 6, cujas estimações usam a subamostra com os bancos cuja participação do crédito nos ativos está abaixo da mediana, indicam que há uma menor sensibilidade do crédito às três medidas de capital no segundo período para esses bancos. Esses resultados são consistentes com a ideia de que a 
sensibilidade crédito-capital seja maior naqueles bancos que têm o crédito como atividade primordial. Ainda assim, os erros-padrão dos coeficientes relativos às medidas de capital nas Tabelas 5 e 6 são maiores do que os obtidos nas Tabelas 3 e 4. Dessa forma, os resultados não permitem concluir categoricamente que a diferença entre os resultados das duas subamostras seja estatisticamente significante.

Tabela 5

Relação do Crescimento do Crédito com Capital Excedente, PL/AT e Basileia (Bancos com Maior Participação de Crédito na Carteira Ativa)

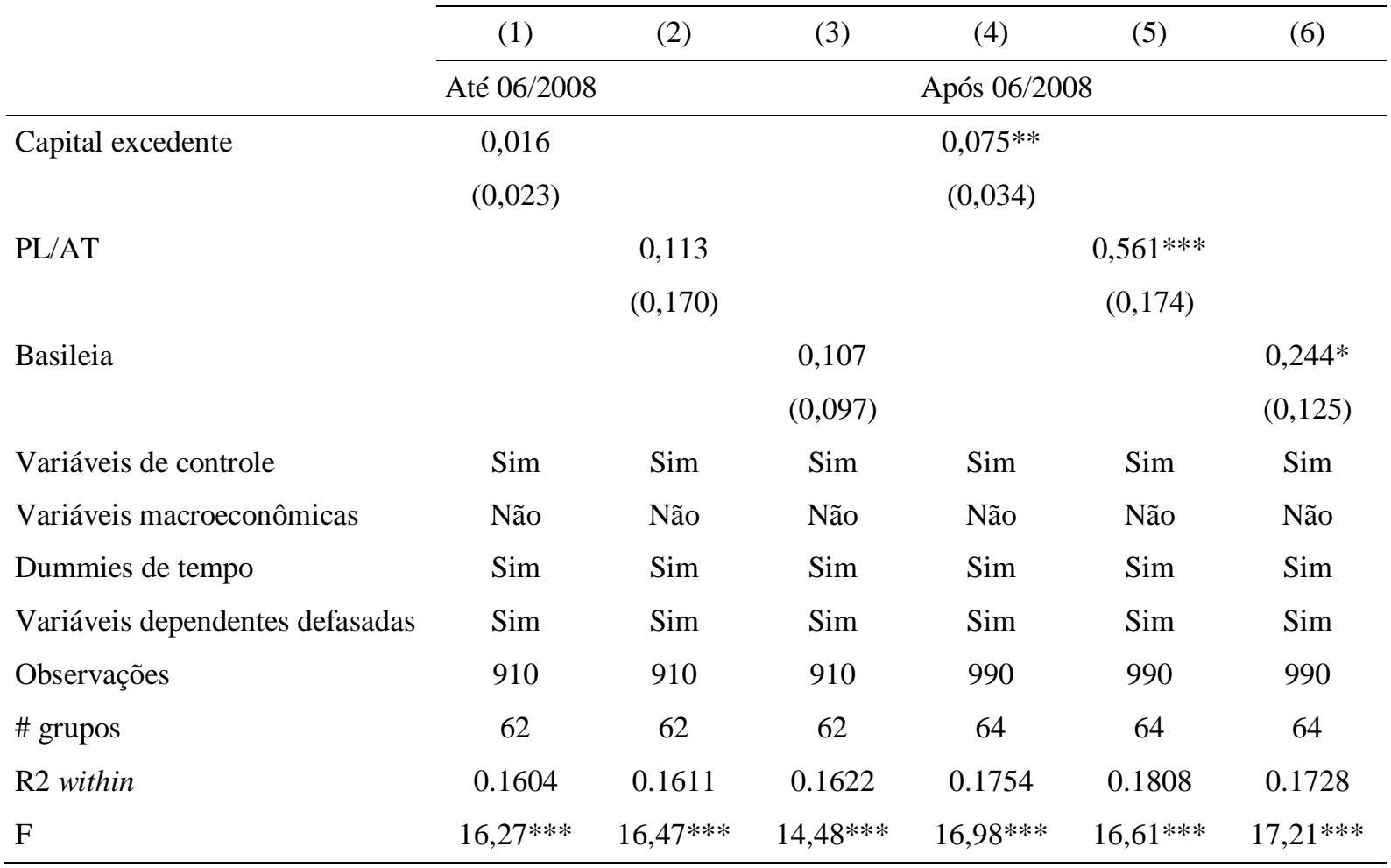

Nota. A estimação é feita com os bancos cuja participação do crédito em relação ao ativo total é superior à mediana amostral em cada período. A variável dependente é o crescimento do crédito livre $\left(\Delta \operatorname{lnCrédito}{ }_{i, t}\right)$, calculado como a variação em logaritmo natural do volume de crédito livre do banco $i$, entre $t$ e $t$ - 1 . As variáveis de interesse são: capital excedente; Patrimônio Líquido sobre Ativo Total (PL/AT) e índice de Basileia (Basileia). As variáveis de controle (não reportadas) são: dummies de tamanho; variáveis de ganhos ROA (Retorno sobre Ativos) e ROA² (quadrado do Retorno sobre Ativos); dummy para pressão regulatória; Baixa de Crédito de Liquidação Duvidosa sobre o Ativo Total; e a participação de Ativos Líquidos no Ativo Total. Todas as variáveis independentes estão defasadas em um período. Todas as especificações foram realizadas através do método OLS FE. Fonte: elaborado pelos autores.

Desvio padrão entre parênteses: ***p<0,01;**p<0,05; *p<0,1. 
Tabela 6

\section{Relação do Crescimento do Crédito com Capital Excedente, PL/AT e Basileia (Bancos com Menor Participação de Crédito na Carteira Ativa)}

\begin{tabular}{lcccccc} 
& $(1)$ & $(2)$ & $(3)$ & $(4)$ & $(5)$ & $(6)$ \\
\hline Capital excedente & 0,049 & & & 0,064 & & \\
& $(0,036)$ & & & $(0,039)$ & & \\
PL/AT & & 0,111 & & & $0,380^{* *}$ & \\
& & $(0,248)$ & & & $(0,155)$ & \\
Basileia & & & 0,039 & & & $0,078^{*}$ \\
& & & $(0,044)$ & & & $(0,046)$ \\
Variáveis de controle & Sim & Sim & Sim & Sim & Sim & Sim \\
Variáveis macroeconômicas & Não & Não & Não & Não & Não & Não \\
Dummies de tempo & Sim & Sim & Sim & Sim & Sim & Sim \\
Variáveis dependentes defasadas & Sim & Sim & Sim & Sim & Sim & Sim \\
Observações & 958 & 959 & 959 & 934 & 935 & 935 \\
\# grupos & 64 & 64 & 64 & 62 & 62 & 62 \\
R2 within & 0.0588 & 0.0556 & 0.0563 & 0.1081 & 0.1132 & 0.1107 \\
F & $3,53^{* * *}$ & $2,95^{* * *}$ & $3,03 * * *$ & $17,02^{* * *}$ & $11,66^{* * * *}$ & $21,46^{* * * *}$ \\
\hline
\end{tabular}

Nota. A estimação é feita com os bancos cuja participação do crédito em relação ao ativo total é inferior à mediana amostral em cada período. A variável dependente é o crescimento do crédito livre $\left(\Delta \operatorname{lnCrédito}{ }_{i, t}\right)$, calculado como a variação em logaritmo natural do volume de crédito livre do banco $i$, entre $t$ e $t$ - 1 . As variáveis de interesse são: capital excedente; Patrimônio Líquido sobre Ativo Total (PL/AT) e índice de Basileia (Basileia). As variáveis de controle (não reportadas) são: dummies de tamanho; variáveis de ganhos ROA (Retorno sobre Ativos) e ROA² (quadrado do Retorno sobre Ativos); dummy para pressão regulatória; Baixa de Crédito de Liquidação Duvidosa sobre o Ativo Total; e a participação de Ativos Líquidos no Ativo Total. Todas as variáveis independentes estão defasadas em um período. Todas as especificações foram realizadas através do método OLS FE. Fonte: elaborado pelos autores.

Desvio padrão entre parênteses: ***p $<0,01 ; * * \mathrm{p}<0,05 ; * \mathrm{p}<0,1$.

\section{Bancos públicos}

Para analisar a relação entre o crescimento do crédito e o capital nos bancos públicos, a equação 8 foi adaptada, incluindo-se uma interação entre uma dummy de banco público e as medidas de capital (capital excedente, PL/AT e Basileia). A Tabela 7 mostra os resultados das estimações. O efeito do capital no crédito em bancos públicos é dado pela soma do coeficiente da variável (sem interação) com o coeficiente da interação entre cada variável e a dummy de banco público. 
Tabela 7

Relação entre Crédito e Capital Excedente nos Bancos Públicos

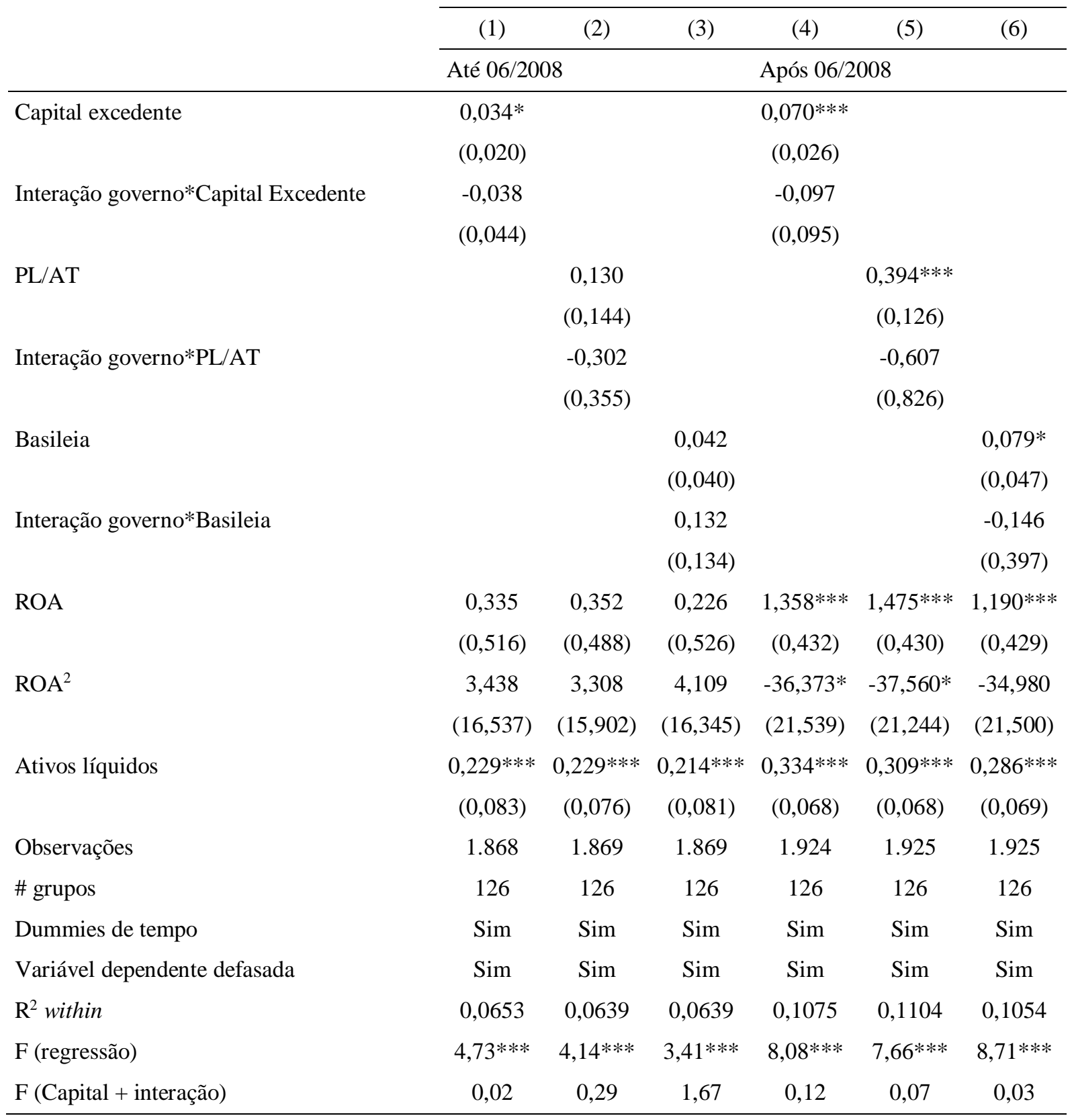

Nota. A variável dependente é o crescimento do crédito livre $\left(\Delta \operatorname{lnCrédito}{ }_{i, t}\right)$, calculado como a variação em logaritmo natural do volume de crédito livre do banco $i$, entre $t$ e $t$ - 1 . As variáveis independentes são: capital excedente OLS FE, calculado conforme equação 1; Patrimônio Líquido sobre Ativo Total (PL/AT); índice de Basileia (Basileia); crescimento do Patrimônio Líquido $(\Delta \mathrm{PL})$; dummies de tamanho (não reportadas); variáveis de ganhos ROA e ROA ${ }^{2}$; dummy para pressão regulatória (não reportada); Baixa de Crédito de Liquidação Duvidosa sobre o Ativo Total (não reportada); e a participação de Ativos Líquidos no Ativo Total. Todas as variáveis independentes estão defasadas em um período. Todas as especificações foram realizadas através do método OLS FE. Fonte: elaborado pelos autores.

Desvio padrão entre parênteses: ***p $<0,01 ; * * \mathrm{p}<0,05 ; * \mathrm{p}<0,1$.

Os resultados mostrados nas colunas (1) e (4) da Tabela 7 mostram que o coeficiente $\beta_{l}$ da variável capital excedente sofre pouquíssima alteração em relação ao encontrado na especificação base (reportado na Tabela 3). Já os coeficientes da interação banco público $\times$ capital excedente são negativos, não significantes, e aproximadamente da mesma magnitude que os coeficientes $\beta_{1}$. O efeito estimado de uma variação de 1 ponto percentual no capital excedente sobre o crédito em bancos públicos 
é dado por: $0,034 \%-0,038 \%=-0,004 \%$ no primeiro período e $0,070 \%-0,097 \%=-0,027 \%$ no segundo período. Os testes $F$ para a soma dos coeficientes (mostrados na última linha da Tabela 7) indicam que os efeitos estimados não são estatisticamente diferentes de zero. Esse resultado indica que a oferta de crédito em bancos públicos não está associada ao capital excedente. Duas possíveis interpretações não excludentes para esse resultado são: (a) os bancos públicos não enfrentam restrição de capital, e portanto o capital é ajustado facilmente conforme a demanda por crédito; (b) a política de crédito em bancos públicos tem determinantes exógenos (por exemplo, políticas públicas) não relacionados ao capital bancário. Por exemplo, a política do governo federal de aumentar o crédito nos bancos públicos pode ter corroborado para a ausência de associação entre o capital excedente e o crédito nestes bancos, sobretudo durante o segundo período ${ }^{(10)}$.

Uma possível preocupação com a validade dos resultados mostrados nas colunas (1) e (4) da Tabela 7 é que os determinantes do capital alvo dos bancos públicos sejam distintos dos demais bancos, o que resultaria num capital excedente mal estimado para esses bancos. As colunas (2), (3), (5) e (6) da Tabela 7 apresentam as especificações incluindo a interação entre a dummy de banco público e os indicadores observáveis de capital (PL/AT e Basileia). Assim como observado para o coeficiente de banco público $\times$ capital excedente, os coeficientes das interações banco público $\times$ PL/AT e banco público $\times$ Basileia não são significativos. $O$ teste $F$ para a soma dos coeficientes de interesse indica que o efeito estimado dos indicadores de capital no crédito em bancos públicos não é estatisticamente diferente de zero. Testes de robustez não reportados, com as variáveis macroeconômicas em substituição às dummies de tempo, resultam em coeficientes similares.

\section{Conclusão}

O efeito do capital bancário sobre o crédito tem tomado a atenção de acadêmicos, profissionais do sistema financeiro e reguladores. Os aportes de capital promovidos pelos governos de diversos países durante a crise do subprime e o aumento do capital regulatório proposto pelo terceiro Acordo de Basileia intensificaram o debate sobre a relação entre capital bancário e crédito. Propondo adaptações ao modelo de Berrospide e Edge (2010), este trabalho realiza um teste empírico associando capital bancário e crédito no mercado brasileiro de 2003 a 2012.

O estudo se divide em duas etapas. Na primeira etapa, estima-se o capital alvo, ativamente gerenciado pelos bancos de acordo com seu risco, características idiossincráticas e expectativas, e calcula-se o capital excedente a partir deste capital otimizado. A estimativa do capital alvo permite uma investigação que ultrapassa as métricas formais estabelecidas pelo capital regulamentar, que pode eventualmente não ser uma variável determinante da oferta de crédito. Na segunda etapa, investiga-se se este capital excedente está associado ao crescimento do crédito.

A amostra é dividida em dois períodos, já que mudanças no ambiente macroeconômico e institucional a partir do final de 2008 (redução na liquidez global após a falência do Lehman Brothers; amadurecimento da economia num ambiente com relativa estabilidade de preços; e adoção de medidas macroprudenciais que exigiram maior alocação de capital para certas modalidades de crédito) sugerem alteração na relação capital bancário e crédito. Essas mudanças e uma maior preocupação com a relação ao risco e à liquidez dos ativos por parte do mercado e dos reguladores parecem ter modificado o custo de oportunidade do capital e o padrão da substituição de ativos.

Os resultados confirmam a hipótese de que o capital excedente se relaciona positivamente ao aumento do crédito, nos dois períodos analisados (entre março de 2003 e junho de 2008; e entre setembro de 2008 e dezembro de 2012). O efeito no segundo período é praticamente o dobro do observado no primeiro período. Ainda assim, esses efeitos podem ser considerados economicamente modestos. $\mathrm{O}$ resultado é robusto à substituição do capital excedente estimado por medidas contábeis diretamente observáveis. 
O impacto estimado do acréscimo de R $\$ 1$ no Patrimônio Líquido, coeteris paribus, é de aproximadamente $\mathrm{R} \$ 0,11$ de acréscimo na carteira de crédito na primeira parte do período amostral (até junho/2008), e de R $\$ 0,24$ no segundo período (a partir de setembro/2008). Apesar das estimativas do efeito do capital bancário sobre o crédito em reais carecerem de maior acurácia - já que o aumento (ou diminuição) do capital está normalmente associado a mudanças em outras variáveis importantes, sobretudo a liquidez - a magnitude dos valores é bastante distinta da sustentada a partir da premissa de alavancagem constante, balizada pelo capital regulatório. Focando em um mercado emergente e com crédito crescente, nossos resultados estão em congruência com os estudos de Berrospide e Edge (2010) em grandes instituições nos EUA e de Francis e Osborne (2009) no Reino Unido, apontando um efeito modesto do capital sobre o crédito.

A segunda hipótese, que investiga se as relações entre o capital excedente e o crescimento do crédito são distintas nas instituições públicas, foi confirmada. Nos bancos públicos, o crescimento do crédito é menos sensível a variações no capital.

As conclusões obtidas devem ser circunstanciadas a cada período e à população analisada. Generalizações possíveis devem ser balizadas, portanto, por características macroeconômicas e institucionais comparáveis. Em especial, o mercado bancário brasileiro tem características peculiares, como a participação importante de bancos públicos, para os quais a relação entre capital e crédito é pouco significante, segundo nossos resultados. Nossos resultados refletem a relação média existente entre capital e crédito nos bancos brasileiros, e é possível que esta relação seja mais forte ou mais fraca do que a encontrada para determinados bancos específicos. Apesar deste trabalho não permitir a prescrição de receituários prontos, os resultados deste trabalho podem subsidiar políticas públicas no Brasil e em outros países em desenvolvimento com características semelhantes.

Estudos posteriores podem analisar os efeitos do Capital Principal, do Capital de Nível I e da PEPR (parcela referente às exposições ponderadas pelo fator de ponderação de risco a elas atribuído) sobre o volume de crédito livre futuro; procurar identificar relação causal na relação entre capital bancário e crédito controlando o efeito de demanda; propor novos cortes amostrais; considerar os efeitos da competição no mercado bancário sobre o capital e o crédito e recalcular os coeficientes para períodos futuros.

\section{Notas}

\footnotetext{
${ }^{1}$ As opiniões expressas pelo autor Valter Takuo Yoshida Junior são exclusivamente de sua responsabilidade e não refletem necessariamente a posição do Banco Central do Brasil.

${ }^{2}$ As variáveis independentes $\operatorname{size}_{u, i, t-1}, R O A_{i, t-1}, R O A_{i, t-1}^{2}$ e $R e g u l a c ̧ a ̃ o_{i, t-1}$ não constam na segunda etapa de Berrospide e Edge (2010). Sendo variáveis presentes no cálculo do capital alvo e, consequentemente, no cálculo do capital excedente, foram incluídas a fim de controlar efeitos parciais que poderiam afetar tanto as medidas de capital excedente como o crescimento do crédito.

${ }^{3}$ A endogeneidade entre capital e crédito não é necessariamente um problema caso se pretenda apenas determinar se o pressuposto de alavancagem constante exagera as estimativas da relação entre crédito e capital, já que esta fonte de endogeneidade induz a um viés positivo na estimativa do coeficiente (Berrospide \& Edge, 2010).
}

${ }^{4}$ Utiliza-se um filtro de modalidade e natureza da operação, procurando utilizar uma base comparável aos números publicados nos balancetes e no relatório TOP50.

${ }^{5}$ Judson, R. A., \& Owen, A. L. (1999). Estimating dynamic panel data models: a guide for macroeconomists. Economics Letters, 65(1), 9-15. doi: 10.1016/S0165-1765(99)00130-5, mostram que o possível viés não é grande em painéis balanceados com mais de 30 períodos. Nosso painel tem 40 períodos, mas não é balanceado. Ainda assim, os resultados similares obtidos a partir das estimações por outros métodos sugerem que eventual viés não deve ser substancial.

${ }^{6}$ Nas regressões em OLS FE AR(1), as 40 dummies de tempo foram substituídas por um controle de sazonalidade (dummies referentes a cada um dos trimestres do ano). Nas regressões em FGLS, é necessário que todos os aspectos do modelo (entre os quais distúrbios com diferentes variâncias para cada painel, porém constantes em cada um deles) estejam completamente satisfeitos para que os desvios padrão sejam apropriados. Como a preocupação principal é com eventuais vieses dos 
coeficientes, e não com a significância estatística dos mesmos, o não atendimento desses pressupostos não representa um problema à estimação.

${ }^{7}$ No $2^{\circ}$ período, o capital alvo mediano é $15,67 \%$. A variação de 1 ponto percentual de PL/AT no capital alvo é de (16,67\% $15,67 \%) / 15,67 \%=6,38 \%$, e o efeito sobre o crédito é $(6,38 \% \times 0,068 \%) / 1 \%$.

${ }^{8}\left(L_{t}-L_{t-1}^{*}\right)=0,032 \times 50,82 \% \times 6,51 \times\left(K_{t}-K_{t}^{*}\right)$, ou $\left(L_{t}-L_{t-1}^{*}\right)=0,11 \times\left(K_{t}-K_{t}^{*}\right)$.

9 No primeiro período, o cálculo é: $\left(L_{t}-L_{t-1}^{*}\right)=0,032 \times 45,23 \% \times 11,46 \times\left(K_{t}-K_{t}^{*}\right)$, ou $\left(L_{t}-L_{t-1}^{*}\right)=0,17 \times$ $\left(K_{t}-K_{t}^{*}\right)$. No segundo, é: $\left(L_{t}-L_{t-1}^{*}\right)=0,068 \times 51,16 \% \times 11,73 \times\left(K_{t}-K_{t}^{*}\right)$, ou $\left(L_{t}-L_{t-1}^{*}\right)=0,41 \times\left(K_{t}-K_{t}^{*}\right)$.

${ }^{10}$ Note-se que não se faz (e nem é o escopo deste estudo) nenhum juízo de valor sobre o efeito dessas políticas em termos de bem-estar econômico e social.

\section{Referências}

Angrist, J. D., \& Pischke, J. (2009). Mostly harmeless econometrics: an empiricist's companion. Princeton, New Jersey: Princeton University Press.

Banco Central do Brasil. (n.d.). 50 maiores bancos e o consolidado do Sistema Financeiro Nacional. Recuperado de www4.bcb.gov.br/top50/port/top50.asp

Banco Central do Brasil. (2002). Sistema de Informações de Crédito. Base de dados. Brasília: Autor.

Berger, A. N., \& Udell, G. F. (1994). Did risk-based capital allocate bank credit and cause a "credit crunch" in the United States? Journal of Money, Credit and Banking, 26(3), 585-628. doi: $10.2307 / 2077994$

Bernanke, B. S., \& Lown, C. S. (1991). The credit crunch \& comments and discussion. Brookings Papers on Economic Activity, 2, 205-247. doi: 10.2307/2534592

Berrospide, J. M., \& Edge, R. M. (2010). The effects of bank capital on lending: what do we know, and what does it mean? International Journal of Central Banking, 6(34), 1-50.

Blum, D., \& Nakane, M. I. (2005, dezembro). O impacto de requerimentos de capital na oferta de crédito bancário no Brasil. Anais do Encontro Nacional de Economia da Associação Nacional dos Centros de Pós-graduação em Economia, Natal, RN, Brasil, 33.

Brei, M., Gambacorta, L., \& Peter, G. von (2013). Rescue packages and bank lending. Journal of Banking \& Finance, 37(2), 490-505. doi: 10.1016/j.jbankfin.2012.09.010

Dawid, P. E., \& Takeda, T. (2011). Recolhimentos compulsórios e o crédito bancário brasileiro [Trabalhos para discussão, $\mathrm{N}^{\circ}$ 250]. Brasília, DF: Banco Central do Brasil.

Diamond, D. W., \& Rajan, R. G. (2000). A theory of bank capital. Journal of Finance, 55(6), 24312465. doi: $10.1111 / 0022-1082.00296$

Elliott, D. J. (2010). A further exploration of bank capital requirements: effects of competition from other financial sectors and effects of size of bank or borrower and of loan type. Washington: Brookings Institution.

Flannery, M. J., \& Rangan, K. P. (2008). What caused the bank capital build-up of the 1990s? Review of Finance, 12(2), 391-429. doi: 10.1093/rof/rfm007

Francis, W., \& Osborne, M. (2009). Bank regulation, capital and credit supply: measuring the impact of prudential standards [Paper, $\mathrm{N}^{\mathrm{o}}$ 36]. Financial Services Authority, Londres, Reino Unido.

Gambacorta, L., \& Mistrulli, P. E. (2004). Does bank capital affect lending behavior? Jounal of Financial Intermediation, 13(4), 436-457. doi: 10.1016/j.jfi.2004.06.001 
Hancock, D., \& Wilcox, J. A. (1993). Has there been a "capital crunch" in banking? The effects on bank lending of real estate market conditions and bank capital shortfalls. Journal of Housing Economics, 3(1), 31-50. doi: 10.1006/jhec.1993.1003

Hancock, D., \& Wilcox, J. A. (1998). The "credit crunch" and the availability of credit to small business. Journal of Banking and Finance, 22(6/8), 983-1014. doi: 10.1016/S0378-4266(98)00040-5

Kristensen, I. P., \& Wawro, G. (2003, July). Lagging the dog? The robustness of panel corrected standard errors in the presence of serial correlation and observation specific effects. Proceedings of the Annual Meeting of the Society for Political Methodology, Minneapolis, MN, USA, 20.

Martins, B., \& Schechtman, R. (2013). Loan pricing following a macro prudential within-sector capital measure [Trabalhos para discussão, $\mathrm{N}^{\mathrm{o}}$ 323]. Brasília, DF: Banco Central do Brasil.

Oliveira, R. F., Schiozer, R. F., \& Barros, L. A. B. C. (2015). Depositors' perception of "too-big-tofail". Review of Finance, 19(2), 191-227. doi: 10.1093/rof/rft057

Oliveira, R. F., Schiozer, R. F., \& Leão, S. (2014). Atuação de bancos estrangeiros no Brasil: mercados de crédito e derivativos de 2005 a 2011. Revista de Administração Mackenzie, 15(2), 162-198.

Peek, J., \& Rosengreen, E. (1995). The capital crunch: neither a borrower nor a lender be. Journal of Money, Credit and Banking, 27(3), 625-638. doi: 10.2307/2077739

Saito, R., \& Pereira, J. A. (2012). How do capital buffers respond to Basel? An empirical analysis of the Brazilian banking system [Working Paper]. Social Science Research Network, Rochester, NY. Retrieved from http://papers.ssrn.com/sol3/papers.cfm?abstract_id=2079633

Stock, J. H., \& Watson, M. W. (2008). Heteroskedasticity-robust standard errors for fixed effects panel data regression. Econometrica, 76(1), 155-174. doi: 10.1111/j.0012-9682.2008.00821.x

Takeda, T., \& Dawid, P. E. (2013). Um estudo sobre comportamento de tomadores e ofertantes no mercado de crédito [Trabalhos para discussão, N 338]. Brasília, DF: Banco Central do Brasil.

\section{Dados dos Autores}

Valter Takuo Yoshida Junior

Av. Paulista, 1804, 01310-922, São Paulo, SP, Brasil. E-mail: valter.yoshida @bcb.gov.br

Rafael Felipe Schiozer

Av. Nove de Julho, 2029, 01313-902, São Paulo, SP, Brasil. E-mail: rafael.schiozer@fgv.br 